\title{
Portal Vein Tumor Thrombosis and Hepatocellular Carcinoma - The Changing Tides
}

\author{
Abdul Rehman Khan (1D ${ }^{1-3}$ \\ Xuyong Wei ${ }^{1,3,4}$ \\ Xiao $\mathrm{Xu}^{\mathrm{l}-4}$ \\ 'Department of Hepatobiliary and \\ Pancreatic Surgery, The Center for \\ Integrated Oncology and Precision \\ Medicine, Affiliated Hangzhou First \\ People's Hospital, Zhejiang University \\ School of Medicine, Hangzhou, 310006, \\ People's Republic of China; ${ }^{2}$ Department \\ of Hepatobiliary and Pancreatic Surgery, \\ The First Affiliated Hospital, Zhejiang \\ University School of Medicine, Hangzhou, \\ 310003, People's Republic of China; \\ ${ }^{3} \mathrm{NHC}$ Key Laboratory of Combined \\ Multi-organ Transplantation, Hangzhou, \\ 310003 , People's Republic of China; \\ ${ }^{4}$ Institute of Organ Transplantation, \\ Zhejiang University, Hangzhou, 310003, \\ People's Republic of China
}

\begin{abstract}
Portal vein involvement is considered one of the most fearful complications of hepatocellular carcinoma (HCC). Portal vein tumor thrombosis (PVTT) is associated with aggressive tumor biology (high grade), high tumor burden (number and size of lesions), high levels of serum markers (AFP), poor liver function (deranged LFT), and poor performance status of patients. The Barcelona Clinic Liver Cancer staging system places HCC patients with PVTT in advanced stage (BCLC Stage-C). This group contains a fairly heterogeneous patient population, previously considered candidates for palliative systemic therapy with sorafenib. However, this provided modest overall survival (OS) benefit. The results of a recent Phase III (IMbrave150) trial favor the combination of atezolizumab and bevacizumab over sorafenib as a standard of care in advanced unresectable HCC. While only lenvatinib proved to be non-inferior against sorafenib in a phase III (REFLECT trial), regorafenib (RESORCE trial), ramucirumab (REACH-2), and cabozantinib (CELESTIAL) have been approved second-line therapy in phase III clinical trials. Recently, the data on the prospect of other modalities in the management of HCC with PVTT is mounting with favorable results. Targeting multiple pathways in the HCC cascade using a combination of drugs and other modalities such as RT, TACE, TARE, and HAIC appear effective for systemic and loco-regional control. The quest for the ideal combination therapy and the sequence set is still widely unanswered and prospective trials are lacking. With the armament of available therapeutic options and the advances and refinements in the delivery system, down-staging patients to make them eligible for curative resection has been reported. In a rapidly evolving treatment landscape, performing surgery when appropriate, in the form of LR and even LT to achieve cure does not seem farfetched. Likewise, adjuvant therapy and prompt management of the recurrences holds the key to prolong OS and DFS. This review discusses the management options of HCC patients with PVTT.
\end{abstract}

Keywords: hepatocellular carcinoma, portal vein tumor thrombosis, systemic therapy, transarterial chemoembolization, hepatic artery infusion chemotherapy, radiotherapy, multimodality treatment, liver resection, liver transplantation

\section{Introduction}

Primary liver cancer is the sixth most commonly diagnosed cancer and the third leading cause of cancer-related deaths worldwide, with approximately 906,000 new cases and 830,000 deaths annually. Hepatocellular carcinoma (HCC), the most common type of primary liver cancer, accounts for $75-85 \%$ of these cases. ${ }^{1}$

HCC arising in the setting of liver cirrhosis can have a spectrum of presentations. The portal vein (PV) involvement is considered one of the fearful complications of HCC. It is involved in $16-30 \%$ of the patients with HCC and has a direct impact on liver function. ${ }^{2-6}$ Advances in the imaging techniques have made early
Correspondence: Xiao Xu

Department of Hepatobiliary and Pancreatic Surgery, The Center for Integrated Oncology and Precision Medicine, Affiliated Hangzhou First People's Hospital, Zhejiang University School of Medicine, Hangzhou, 310006 , People's Republic of China

Email zjxu@zju.edu.cn 
diagnosis and precise characterization of the liver lesions possible. ${ }^{7,8}$ However, a large number of patients present late in the course of the disease. ${ }^{9}$ The present recommendations from the European Association for the Study of the Liver (EASL) and previous guidelines from the American Association for the Study of Liver Diseases (AASLD) endorse the Barcelona Clinic Liver Cancer (BCLC) staging system for the management and prognostic prediction of HCC. ${ }^{10-12}$ Any HCC patient with portal vein tumor thrombus (PVTT) is classified as advanced stage (BCLC stage $C$ ) and a candidate for palliative systemic therapy only. ${ }^{10-12}$

Sorafenib was approved as the systemic therapy for unresectable HCC patients on the basis of the SHARP study and Asia Pacific study, both being multicenter, Phase III, double-blind, placebo-controlled trials. They reported an OS benefit of around 3 months in these patients, showing modest benefits. ${ }^{13-15}$

HCC patients are a heterogeneous population with diverse disease behavior and need a personalized management plan. ${ }^{16-18}$ In this multidisciplinary management era, utilizing different modalities delivered either concomitantly or in a set sequence in the HCC patients with PVTT, abundant work is still unconcluded. ${ }^{19,20}$ This review discusses the present status and future perspective of the management of the HCC patients with PVTT.

\section{Guidelines on the Management HCC with PVTT}

The BCLC staging classification consists of four stages and is based on the extent of the primary tumor, vascular invasion and extrahepatic spread, presence of symptoms, performance status (PS) score (the Eastern Cooperative Oncology Group scale), and Okuda stage. The patients are staged as follows: Stage 0 (very early $\mathrm{HCC}$ ); stage A (early HCC, subdivided into A1-A4); stage B (Intermediate $\mathrm{HCC}$ ); stage $\mathrm{C}$ (advanced $\mathrm{HCC}$ ); and stage D (end stage HCC). The reported 5-year survival rate for BCLC 0 -A is $50-70 \%$; the 2-year survival rate for $\mathrm{BCLC} \mathrm{B}$ is $63 \%$; and the 1-year survival rate for BCLC B, $\mathrm{C}$, and $\mathrm{D}$ is $82 \%, 44 \%$, and $11 \%$, respectively. ${ }^{21-23}$

Recently this system has been under heaps of criticism for it does not take a patient centered approach and also associates each stage to a favored treatment option. ${ }^{24}$ Due to a high case burden in some countries, a more aggressive management approach for advanced HCC cases is being adopted based on the clinical experiences and opinions of the expert panels. Researchers in the East, West, and Asia differ with some of the treatment strategies proposed by the BCLC Staging and therefore have devised several staging systems or scores to provide clinical classification of HCC. The French classification, the Cancer of the Liver Italian Program (CLIP), the Chinese University Prognostic Index (CUPI), the Hong Kong Liver Cancer (HKLC) staging system, and the Japanese Integrated Staging (JIS) are some of the comprehensive staging systems that have been developed and validated. ${ }^{25-29}$

So far, there is a lack of consensus on the management of HCC with different grades of PVTT, thus there are numerous guidelines based on various opinions and classification systems (summarized in Figure 1). ${ }^{10,11,30-34}$

\section{Risk Factors for PVTT Formation}

A number of factors have been reported to contribute to the formation of PVTT. A recent study divided patients into two major clusters based on the genomic profiling, landscape of mutations, and critical pathways involved in the development and progression of HCC: Proliferative and Non-proliferative. ${ }^{35}$ 1) The proliferative class had high rates of chromosomal instability, micro-RNA deregulations, and enrichment in aberrant epigenetic signatures. These patients had aggressive tumor biology, high AFP levels, more frequent vascular invasion, and high grade and poor cell differentiation on histology. All of these features can be correlated with poor survival and high rates of recurrence after surgery. HBV-related HCC tumors often belong to this class. ${ }^{36}$ 2) In the non-proliferative class, the transcriptome of the tumor looked a lot like a normal liver. These patients had less aggressive tumor biology, lower AFP, and better cell differentiation. HCV and alcohol-related HCC patients were more common in this class.

The analysis of dysregulated genes between HCC and PVTT has suggested that the extracellular matrix receptor interaction is correlated with the venous metastases of HCC. $^{37}$ Other factors such as the vascular endothelial cells, immune cells in the tumor microenvironment, genomic irregularities, sequential alterations of mRNA expression, DNA methylation of differentially expressed genes, cancer stem cells, dysregulation of extracellular matrix organization, and focal adhesion have all been proposed to contribute to the development of PVTT. ${ }^{38-41}$

HBV infection and active replication has also been implicated in the vascular invasion in HCC patients. ${ }^{42}$ 

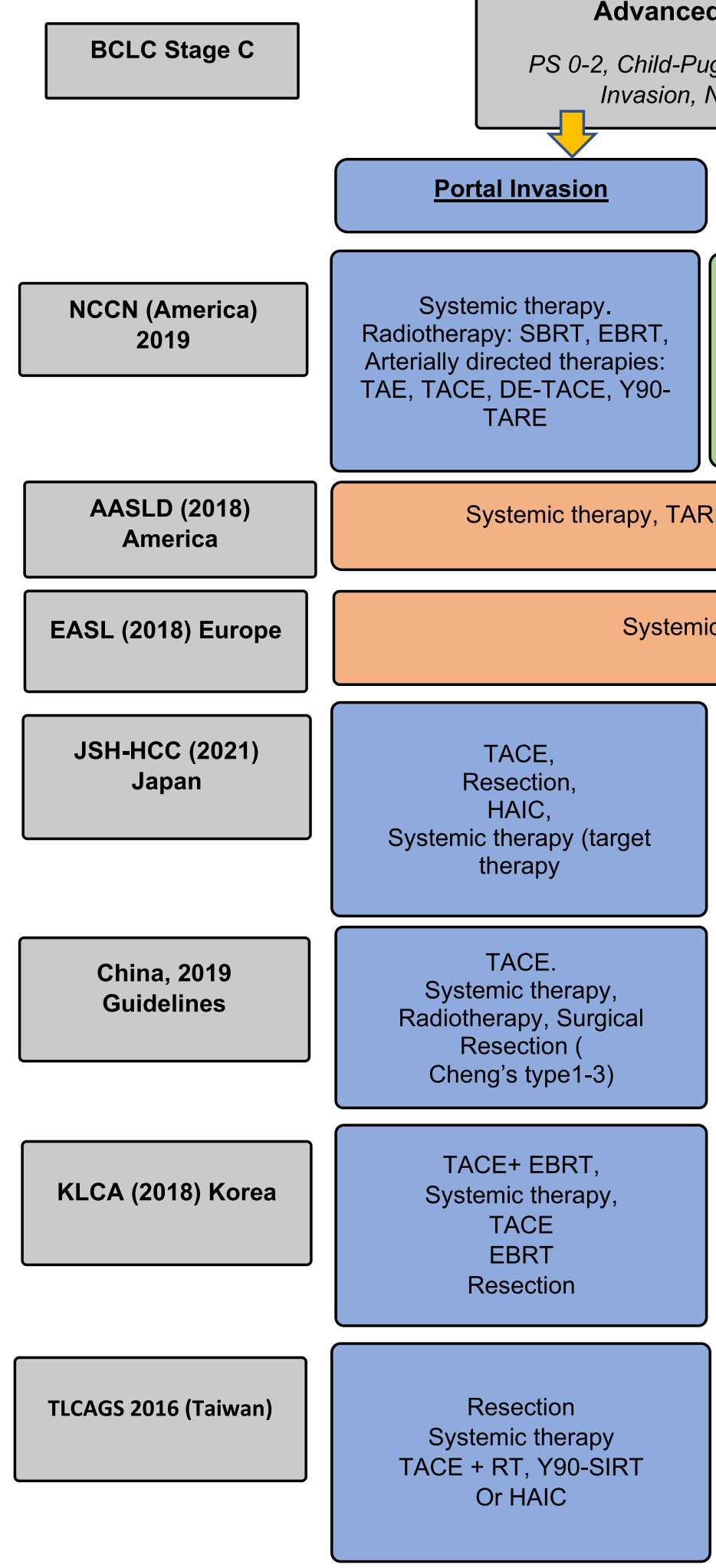

TACE

Resection,

HAIC,

Systemic therapy (target therapy

\section{Systemic therapy}

Best supportive care, Clinical trials, Systemic therapy

\section{N1, M1}

Radiotherapy: SBRT, EBRT, Arterially directed therapies: TARE

Systemic therapy, TARE, Best supportive care

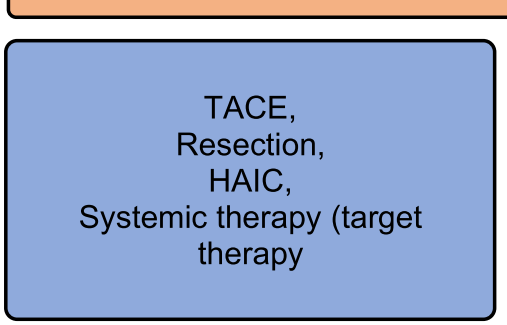

TACE.

Systemic therapy, Radiotherapy, Surgical

Resection ( Cheng's type1-3)

TACE+ EBRT, Systemic therapy, TACE EBRT

Resection

\section{Resection}

Systemic therapy TACE + RT, Y90-SIRT Or HAIC
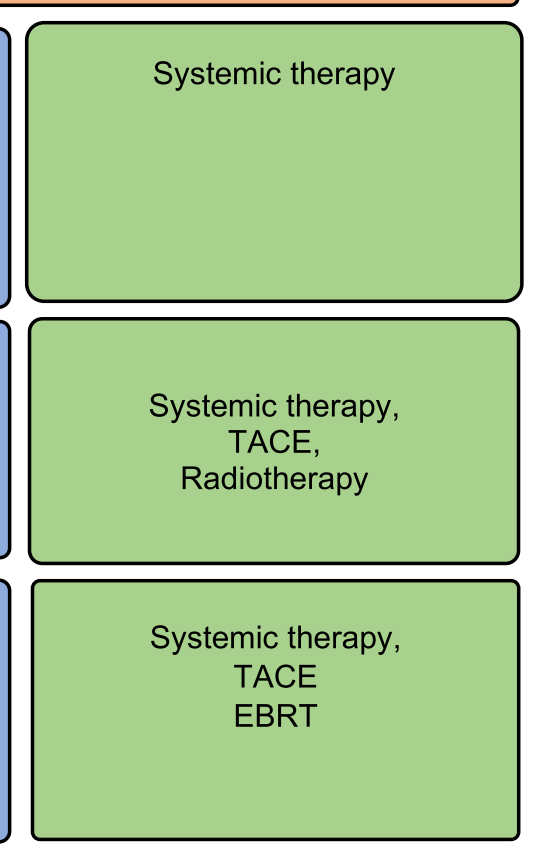

Systemic therapy,

TACE,

TARE,

Radiotherapy,

Palliative care

Figure I Management of advanced hepatocellular carcinoma according to different guidelines. 
The effect of the seropositivity of $\mathrm{HBeAg}(\mathrm{OR}=1.67$, $P=0.046)$, tumor diameter $>3 \mathrm{~cm}(\mathrm{OR}=8.86, P<0.001)$, incomplete or absent encapsulation $(\mathrm{OR}=3.59, P=0.003)$ and DCP $>100 \mathrm{mAU} / \mathrm{mL}(\mathrm{OR}=2.90, P=0.022)$ have been linked with the presence of PVTT, while anti-viral treatment $(P=0.015)$ has been suggested to significantly lower the risk of developing PVTT as well as early tumor recurrence after partial hepatectomy. ${ }^{42-44}$

Direct invasion of the portal vein by the HCC has also been proposed. ${ }^{45}$ Involvement of the portal vasculature leads to the development of portal hypertension and its complications such as formation of the venous collaterals and gastro-esophageal varices. ${ }^{46}$ There is a positive association between the presence of the PVTT and hemorrhagic events in HCC patients. ${ }^{47}$

A study reported that the estimated time for a tumor thrombus (TT) that is present in the 2nd portal branch to grow into the ipsilateral 1st portal branch and from the 1st portal branch to the main portal vein trunk was 8.2 and 11.5 days (median estimated time), respectively. ${ }^{48}$ The extent of the PVTT itself is an independent risk factor for rapid progression of TT. The presence and extension of vascular invasion along with the performance status and ascites have a significant impact on patient survival and the choice of therapeutics. ${ }^{49}$

With the presence of aforementioned factors and most treatments being contraindicated in this setting, these patients perform poor with lower median OS of 2-4 months after best supportive care (BSC). ${ }^{50}$

\section{Portal Vein Tumor Thrombus Classifications}

A number of classifications have been proposed. One of the simplified classifications proposed by $\mathrm{Xu}^{51}$ divides patients with HCC and PVTT in two groups: Group A with tumor thrombus (TT) involving the main PV trunk or both the right and the left portal veins; Group $\mathrm{B}$ with TT involving either the right or the left portal vein branch. The 1-year overall survival (OS) rate of group A after LR was $31.5 \%$. While the reported 1-, 3-, and 5 -year OS rate of group B was $62.3 \%, 16.1 \%$, and $5.2 \%$, respectively.

The Liver Cancer Study Group of Japan classify PVTT into five grades on the degree of tumor involvement. VP0: No tumor thrombus in the portal vein; VP1 includes the presence of a TT distal to the second-order branches of the portal vein (but no direct involvement); VP2 is invasion of the second order branches of the portal vein; VP3 is the presence of the TT in the first-order branch; VP4 includes TT in the main trunk of the portal vein or a portal vein branch contralateral to the primarily involved lobe (or both). The 1-, 3- and 5- year survival rates for PVTT types after resection were as follows: VP0: 91.6\%, $74.2 \%$, and $57.6 \%$; VP1: $78.6 \%, 52.6 \%$, and $38.7 \%$, VP2: $59.2 \%, 31.8 \%$, and $23.8 \%$; VP3 or VP4: $50.4 \%$, $25.8 \%$, and $18.4 \%$, respectively (Figure 2). ${ }^{52,53}$

The classification proposed by Shi et $\mathrm{al}^{55}$ (Cheng's classification) divided the patients into five types depending upon the extent of tumor thrombus in the PV: Type I $\Theta$ indicating microscopic portal invasion, Type I: TT involving the segmental branches of portal vein, Type II: TT involving the right/left portal vein, Type III: TT involving the main portal vein, and Type IV: TT involving the superior mesenteric vein. The 1-, 2- and 3-year OS rates for PVTT types were: Type I: $54.8 \%, 33.9 \%$, and $26.7 \%$; Type II: $36.4 \%$, $24.9 \%$, and $16.9 \%$; Type III: $25.9 \%, 12.9 \%$, and $3.7 \%$; and Type IV: $11.1 \%, 0 \%$, and $0 \%$, respectively (Figure 2 ). ${ }^{54,55}$

\section{Diagnostic Approach}

The contrast enhanced compute tomography (CECT) and magnetic resonance imaging (MRI) are frequently used to detect and distinguish benign from malignant portal vein thrombosis with the sensitivity of $86 \%$ and $100 \%$ and specificity of $100 \%$ and $90 \%$, respectively. ${ }^{56,57}$ Recently, a CT texture analysis software using features such as thrombus density, attenuation of pixels and entropy on CT images has shown that it can be used to characterize portal vein thrombosis and differentiate benign from neoplastic PVTT. $^{58}$

Another excellent imaging method to perceive metabolic defects in the thrombus and differentiate malignant from benign lesion is 18F-Fluorodeoxyglucose positron emission tomography CT (18F-FDG PET CT). For a lesion to be malignant, $\mathrm{Hu}^{59}$ used the criteria of visual analysis and maximum standardized uptake value of (SUVmax) $>3.35$.

\section{Prognostic Scoring Systems Based on the Classification of PVTT}

Few prognostic scoring systems (PSS) based on the classification of PVTT to predict response to given therapy have been proposed.

To predict response to Yttrium-90 (Y90) Radioembolization (RE) among advanced HCC patients 

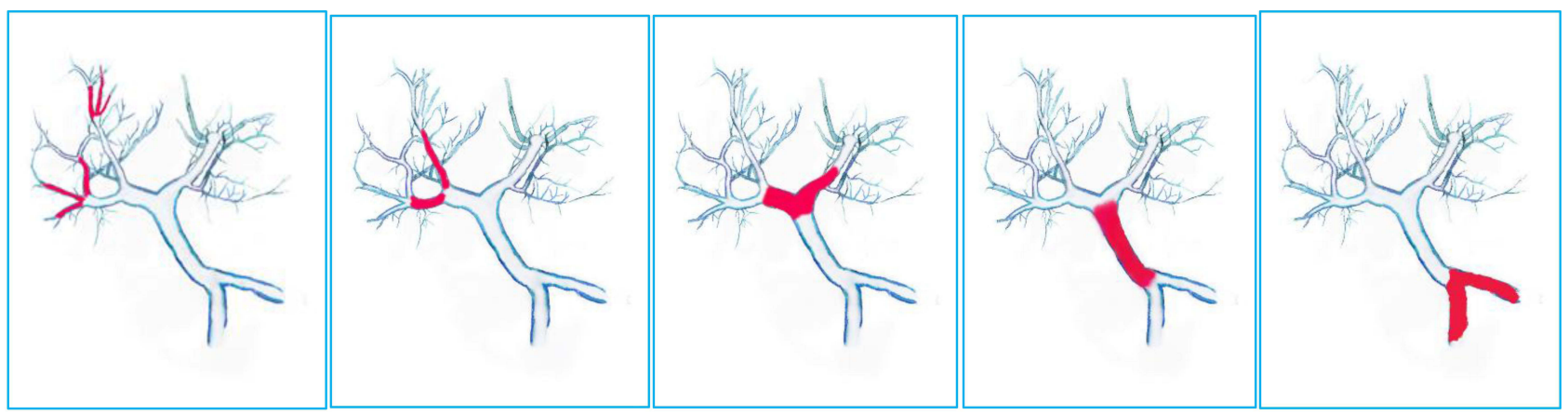

A

B

C

D

E

F

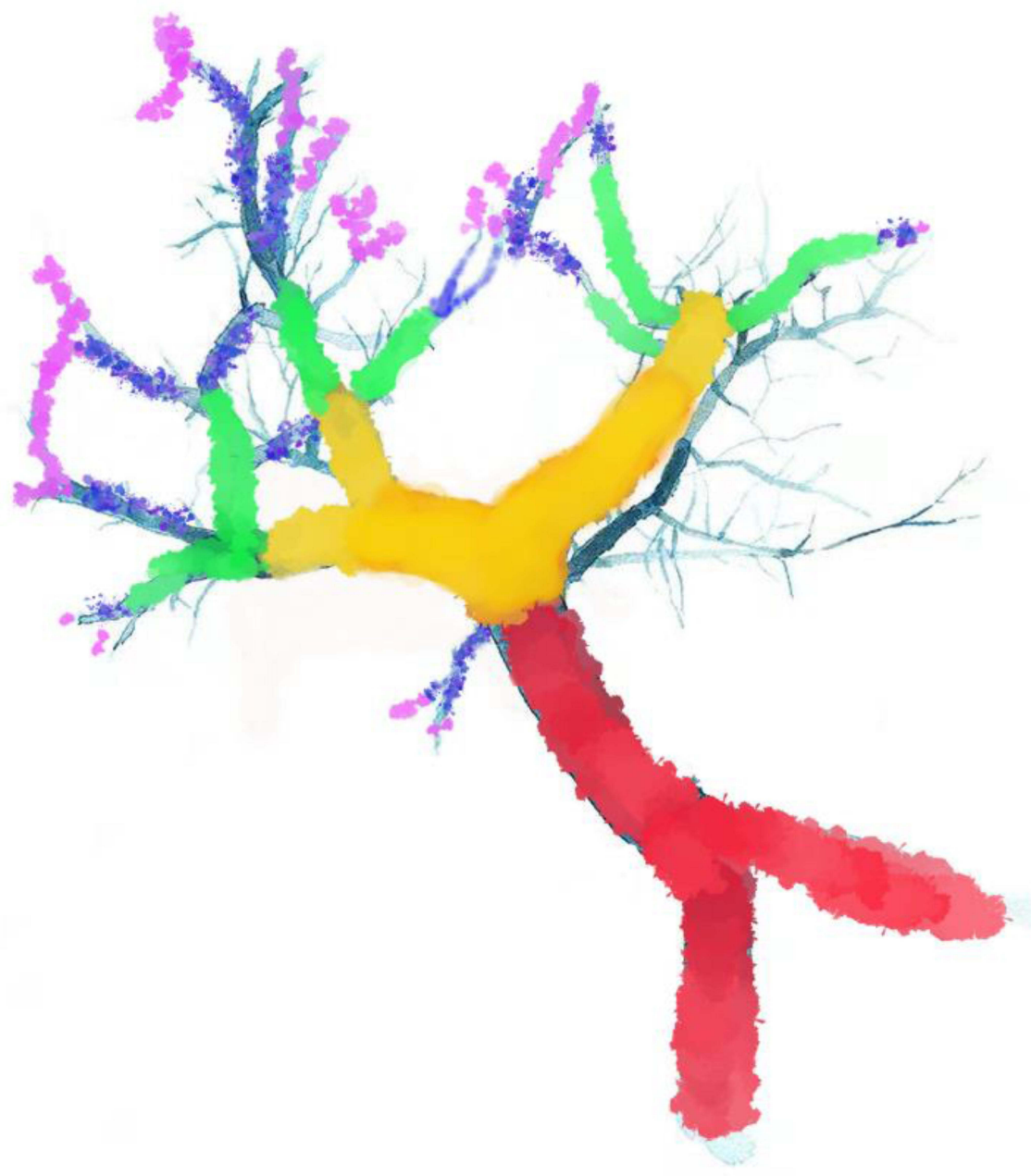

Figure 2 Portal Vein Tumor Thrombus Classification. (A) Japanese VPI: presence of thrombus distal to second order branches. (B) VP2: thrombus in second order branches (left/right portal vein branches). (C) VP3: thrombus in first order branches (left/right portal vein. (D) VP4: thrombus in main trunk of portal vein. (E) Shi et al classification Type IV=tumor thrombus in SMV. Type III=VP4. Type II=VP3. Type I=VPI-2. (F) Based on the extent of involvement of the portal vein by the tumor thrombus, the portal vein can be coded with colors of the rainbow. Portal Vein trunk=red. First order branches=orange. Second order branches=yellow. Distal to second order branches=green. Microvascular Invasion level= blue and purple. MVI, classified as VPI in Japanese and type I by Shi et al, is usually diagnosed on explant pathology. ${ }^{55}$ 
$(\mathrm{n}=120)$ (PVTT VP1-3) with good liver function, Mazzaferro et al proposed PSS based on the factors linked with post-treatment survival. These include bilirubin level $(\leq 1.2 \mathrm{mg} / \mathrm{dL}=$ score 0 and if $>1.2 \mathrm{mg} / \mathrm{dL}=2)$, extension of the PVTT (type $\mathrm{I}=1$, type $\mathrm{II}=2$, type $\mathrm{III}=3$ ), and total tumor burden $(\leq 50 \%$ volume $=0$ and $>50 \%=2)$. Based on the sum up score, the following three prognostic categories were identified: Favorable prognosis ( 0 points), intermediate prognosis (2-3 points), and dismal prognosis ( $>3$ points). The median overall survival (OS) was 14.1 months $(95 \%$ $\mathrm{CI}=10.7-17.5)$, while 1 - and 3-year OS was $53.2 \%$ and $18.5 \%$, respectively. Median OS in the three categories was $32.2,14.9$, and 7.8 months, respectively $(P<0.0001) .^{60}$

For HCC patients with PVTT (Cheng's type I and II) who underwent R0 hepatectomy, Zhang et $\mathrm{al}^{61}$ (multicenter retrospective study) proposed an equation that incorporated the following factors: Total bilirubin $(<17.1 \mu \mathrm{mol} / \mathrm{L}$ score $=0$ and if $\geq 17.1 \mu \mathrm{mol} / \mathrm{L}=1)$, AFP $(<20 \mathrm{ng} / \mathrm{mL}=0 ; \geq 20 \mathrm{ng} / \mathrm{mL}=2)$, tumor diameter $(<3 \mathrm{~cm}=0 ; 3-5 \mathrm{~cm}=1 ;>5 \mathrm{~cm}=2)$, and satellite lesions $(\mathrm{No}=0, \mathrm{Yes}=1)$. Based on the sum up score, patients were divided into two groups: The group with a score $\leq 3$ and the other group with a score $>3$. For patients with a score $\leq 3$ $(n=84)$, the median OS was 19.0 months and for a score $>3$, it was 8.9 months. This PSS has been validated on a prospective internal cohort as well as three independent external cohorts by showing the difference in the median OS among two groups.

Recently, the $\alpha$-fetoprotein (AFP), des- $\gamma$-carboxy prothrombin (DCP), and tumor volume (TV) were reported to provide predictive prognosis in the $\mathrm{HCC}$ patients with type III PVTT undergoing resection. ${ }^{62}$ This ADV score is calculated as $\alpha$-FP $[\mathrm{ng} / \mathrm{mL}] \times \mathrm{DCP} \quad[\mathrm{mAU} / \mathrm{mL}] \times \mathrm{TV} \quad[\mathrm{mL}]$ (expressed in $\log 10$ ) for predicting patient survival after resection. Previously this score has been devised and validated in the patients with solitary as well as large HCC. ${ }^{63-65}$

Low serum concentrations of DCP and curative resection have been suggested as positive factors to 5-year survival after LR in type VP4 PVTT. ${ }^{66}$ It has also been observed that HCC patients with VP1-VP2 undergoing LR had better prognosis when the spleen was not enlarged as compared to the patients having splenomegaly. Further, if the patients with splenomegaly underwent concomitant splenectomy along with LR then the prognosis improved. ${ }^{67}$

\section{Treatment Options for HCC with PVTT}

Treatment modalities for PVTT can be largely classified as local, locoregional and systemic therapies. A) Local therapies include surgery (liver resection and liver transplantation) and radiotherapy (3D-CRT, EBRT). B) Locoregional therapies include TACE, TARE (SIRT), and HAIC. C) Systemic therapies include drugs that fall in the category of Immunotherapy (eg, nivolumab, pembrolizumab), and target therapy (eg, Sorafenib, Regorafenib, Lenvatinib, etc.).

\section{Systemic Therapy}

Among tyrosine kinase inhibitors (TKIs), sorafenib (SHARP trial) and lenvatinib (REFLECT trial) were the only two drugs previously approved as first line therapy for advanced HCC. ${ }^{68,69}$ In a phase III, multicenter, noninferiority trial of advanced unresectable HCC patients $(n=954)$, the median OS was 13.6 months and 12.3 months for the lenvatinib group $(n=478)$ and sorafenib group $(n=476)$, respectively. Lenvatinib also proved to be noninferior with comparable OS and an acceptable safety profile. However, its efficacy among the patients having involvement of the main trunk of the portal vein (VP4) has not been proven in a recent multicenter analysis. ${ }^{69}$

Recently, the combination of atezolizumab plus bevacizumab (Ate-Bevac) has shown better OS as compared to sorafenib as a first line therapy for advanced HCC. In a phase III global trial on advanced HCC patients (PS 01 and $\mathrm{CP}$ class A) who had not been previously treated, the OS at 1 year among patients receiving Ate-Bevac $(n=336)$ was $67.2 \%(95 \% \mathrm{CI}=61.3-73.1)$, while in the sorafenib group $(n=165)$ it was $54.6 \%(95 \% \quad C I=45.2-64.0)$. The progression free survival (PFS) was also significantly longer with Ate-Bevac combination than sorafenib (median PFS 6.8 months $(95 \% \mathrm{CI}=5.7-8.3)$ and 4.3 months (95\% CI $=4.0-5.6)$, respectively. The most common grade 3-4 adverse event reported with Ate-Bevac combination was hypertension (15.2\%). The patient's quality-of-life, physical functioning, as well as role functioning was also better among patients receiving Ate-Bevac. ${ }^{70,71}$ This systemic combination therapy has been recommended as first line therapy among HCC patients with PVTT.

The drugs that have been approved in phase III trials as second line therapy include regorafenib (RESORCE trial), ramucirumab (REACH-2), and cabozantinib (CELESTIAL). ${ }^{72-74}$ The immune-check point inhibitor (ICI), nivolumab in an open label phase I/II (CheckMate 040) trial, irrespective of the line of therapy, has also been approved, while its combination with ipilimumab reported manageable safety. ${ }^{75,76}$ Another ICI, pembrolizumab as second line drug in an open label Phase II trial, has 
Table I Selected Studies on Systemic Therapy for Advanced Hepatocellular Carcinoma with Portal Vein Tumor Thrombosis

\begin{tabular}{|c|c|c|c|c|c|c|}
\hline $\begin{array}{l}\text { Authorl } \\
\text { Trial (Year) } \\
\text { Reference }\end{array}$ & $\begin{array}{l}\text { Modality/ Study } \\
\text { Type }\end{array}$ & $\begin{array}{l}\text { PVTT } \\
\text { Typel PS }\end{array}$ & $\begin{array}{l}\text { No. of } \\
\text { Patients } \\
\text { (n) }\end{array}$ & $\begin{array}{l}\text { Survival Outcome } \\
\text { OS }\end{array}$ & Other Outcomes & $\begin{array}{l}\text { Adverse Events } \geq \text { Grade } \\
3(\%)\end{array}$ \\
\hline $\begin{array}{l}\text { SHARP trial } \\
(2012)^{68}\end{array}$ & Sorafenib & $\begin{array}{l}\text { MVI (Ps 0- } \\
\mathrm{I} ; \mathrm{CP} \mathrm{A})\end{array}$ & 108 & MST, 8.I months & $\begin{array}{l}\text { TTP (months) } 4.1 \\
\text { DCR (\%) } 38.9\end{array}$ & NA \\
\hline $\begin{array}{l}\text { Jeong et al } \\
(2013)^{15}\end{array}$ & Sorafenib & VP3 VP4 & $6 ; 24$ & MST; 3.1 months & $\begin{array}{l}\text { TTP (months) 2.I. } \\
\text { ORR (months I } 3.3 \\
\text { DCR (\%) } 45.0\end{array}$ & $\begin{array}{l}\text { Fatigue (10), HFSR (3.3), } \\
\text { Liver dysfunction (3.3) }\end{array}$ \\
\hline $\begin{array}{l}\text { Song et al } \\
(2015)^{111}\end{array}$ & $\begin{array}{l}\text { HAIC } \\
\text { versus Sorafenib }\end{array}$ & $\begin{array}{l}\text { MVI } \\
\text { VP2 VP3 } \\
\text { VP4 }\end{array}$ & $\begin{array}{l}110 \\
\text { versus } 60 \\
(5,16,39)\end{array}$ & $\begin{array}{l}\text { Median OS } \\
7.1 \text { versus } 5.5 \text { months }\end{array}$ & $\begin{array}{l}\text { TTP (months) } 3.3 \\
\text { versus } 2.1 \\
\text { ORR; I } 3.3 \text { months } \\
\text { DCR; } 45.0 \text { months }\end{array}$ & $\begin{array}{l}\text { Sorafenib: } \\
\text { Diarrhea (13), Fatigue (8), } \\
\text { HFSR (7), Rash (3) }\end{array}$ \\
\hline $\begin{array}{l}\text { REFLECT } \\
\text { trial }(20 \mid 8)^{69}\end{array}$ & $\begin{array}{l}\text { Lenvatinib } \\
\text { versus Sorafenib }\end{array}$ & $\begin{array}{l}\text { MVI (VP4 } \\
\text { excluded)/ } \\
\text { PS 0-I }\end{array}$ & $\begin{array}{l}109 \\
(22.8 \%) \\
\text { versus } 90 \\
(18.9 \%)\end{array}$ & $\begin{array}{l}\text { Median OS } \\
13.6 \text { versus } 12.3 \\
\text { months }\end{array}$ & 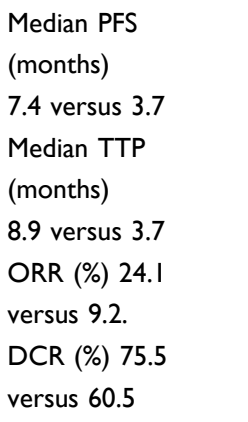 & $\begin{array}{l}\text { Lenvatinib: } \\
\text { HTN (42.2), diarrhea (38.7), } \\
\text { appetite loss (34.0), weight } \\
\text { loss (30.9). } \\
\text { Sorafenib: } \\
\text { HFSR (52.4) diarrhea (46.3), } \\
\text { HTN (30.3), appetite loss } \\
(26.7)\end{array}$ \\
\hline $\begin{array}{l}\text { Richard et al. } \\
(2020)^{70}\end{array}$ & $\begin{array}{l}\text { Atezolizumab- } \\
\text { Bevacizumab } \\
\text { versus Sorafenib }\end{array}$ & $\begin{array}{l}\mathrm{MVI} /(\mathrm{PS} \\
0-\mathrm{I}, \mathrm{CP} \\
\mathrm{A}-\mathrm{C})\end{array}$ & $\begin{array}{l}129(38 \%) \\
\text { versus } 7 \mid \\
(43 \%)\end{array}$ & $\begin{array}{l}\text { At } 6 \text { and } 12 \text { months } \\
84.4 \text { and } 67.2(\%) \\
\text { versus } 72.2 \text { and } 54.6 \\
\text { (\%), respectively }\end{array}$ & $\begin{array}{l}\text { Median PFS } \\
\text { (months) } \\
6.8 \text { versus } 4.3 \\
\text { ORR (\%) } 32.2 \\
\text { versus } 13.3 \\
\text { DCR (\%) } 73.6 \% \\
\text { versus } 55.3 \%\end{array}$ & $\begin{array}{l}\text { Atezolizumab-Bevacizumab } \\
\text { HTN (I5.2), Liver } \\
\text { dysfunction (I0.6), } \\
\text { Sorafenib } \\
\text { HTN (I2.2), HFSD (8.3) }\end{array}$ \\
\hline
\end{tabular}

Abbreviations: PVTT, portal vein tumor thrombosis; PS, performance status; CP, Child-Pugh class; OS, overall survival; PFS, progression free survival; MVI, macrovascular invasion; MST, median survival time; TTP, time to progression; DCR, disease control rate; ORR, objective response rate; Gr, Grade; HFSR, hand foot syndrome; HTN, hypertension.

also been approved in the US as second line therapy ${ }^{77}$ (Table 1).

\section{Radiotherapy}

The high-energy targeted radiations damage cancer cells leading to cell apoptosis. Radiation also induces cellular inflammation and enhances the immune recognition of the tumor cells. ${ }^{78-80}$ Radiation therapy (RT) has long been a component of local-regional control among all the stages of HCC.

The 3-dimensional conformal radiotherapy (3DCRT) and stereotactic body radiation therapy (SBRT) are the most common forms of external beam radiotherapy (EBRT) in practice. 3DCRT utilizes CT based planning to target the lesion, while SBRT is the most advanced form with maximum therapeutic efficacy by concentrating high doses on the targeted tumor area in a short period of time. ${ }^{81}$ Both of these thus spare the normal liver parenchyma from radiation damage. Irrespective of the involvement of vessels or location of the tumor, ERBT can be used as an effective palliative modality for locally advanced HCC. ${ }^{82}$ A recent meta-analysis reported similar OS and disease control rate with both the 3DCRT and SBRT among HCC cases with PVTT. ${ }^{83}$

EBRT was reported as one of the most favorite treatment options in a recent online survey from Korea (161 HCC clinicians), for the HCC patients with vessel involvement (78.9\% participants) or incomplete response after TACE (70.2\% participants). ${ }^{84}$ Recent open label RCT comparing the efficacy and safety of combining EBRT 
with TACE versus sorafenib among HCC patients with macrovascular involvement $(n=90)$ reported a higher radiological response rate at 24 weeks (33.3\% versus $2.2 \%)$, longer median time to progression (31.0 versus 11.7 weeks; $P<0.001$ ), and significantly longer OS (55.0 versus 43.0 weeks; $P=0.04)$ with a EBRT-TACE combination. $^{85}$

A recent study ( $n=14$; type III-IV PVTT) reported tumor thrombus tends to be more sensitive to RT than the primary tumor. The techniques of the CT-MRI image fusion software to better localize target volume site and the intensity modulated RT for better radiation distribution were used. Results stated that $88.9 \%(n=8)$ of patients with primary HCC and all $100 \% \quad(n=5)$ with other types of cancers with PVTT were successfully downstaged from stage IV/III to stage II. ${ }^{86}$ Radiotherapy has also been shown to be more effective in the management of VP3-4 than sorafenib (median OS 10.9 versus 4.8 months, respectively). ${ }^{87}$

RT has also been suggested in various forms and combinations in the setting of advanced HCC. Combinations of 3D CRT and HAIC, intermittent modulated radiotherapy (IM-RT) plus TACE and sorafenib, and 3D CRT plus portal vein stent placement along with TACE and sorafenib have reported better outcomes in the setting of HCC with VP3 and VP4 PVTT. ${ }^{88-90}$ This combination provides survival benefits to HAIC non-responders as well. ${ }^{91}$

A systemic review and meta-analysis comprising 25 studies (patients $=2,577$, randomized control trials (RCTs) $=11$, and non-RCTs=14), comparing TACE plus RT versus TACE alone in advanced unresectable $\mathrm{HCC}$ reported significantly better 1-, 2-, and 3-year survival among patients receiving TACE plus RT. ${ }^{92}$ There can be a number of reasons behind the effectiveness of this approach: The TACE damages a large number of the cancer cells and hence decreases tumor burden as well as radiation field. ${ }^{93,94}$ Also, the decrease in the number of cancer cells causes the cancer cells to divide rapidly, which makes them more radiosensitive. ${ }^{93}$ Furthermore, the RT can reach cancer cells at the periphery of the tumor that take collateral blood supply, it also prolongs retention of anti-cancer drugs. This makes more time available for the drugs to work and hence a smaller number of TACE session are required. ${ }^{95}$

Concurrent liver directed chemoradiotherapy for HCC patients with major PVTT has also been proposed, while another study suggested a possible role of RT as downstaging to living donor LT for HCC with PVTT $^{96,97}$ (Table 2).

\section{Selective Internal Radiation Therapy (SIRT)}

Selective internal radiation therapy (SIRT) is a form of transarterial radioembolization (TARE) by which radioactive element yttrium-90 (Y90) contained in microspheres are delivered to the targeted area through the feeding arteries. The Y90 releases beta particles and causes nearby tissue injury via production of oxygen free radicals. These beta particles have maximum tissue penetration of $10 \mathrm{~mm}$ and a half-life of 64.2 hours. This way delivering the radiation particles directly to the tumor spares the rest of the normal liver tissue from radiation damage. At present, only TheraSphere ${ }^{\circledR}$, a glass-based microsphere containing Y90 is approved by FDA for radiation and as neoadjuvant treatment to resection or transplantation in HCC patients with advanced disease. ${ }^{98-100}$

There have been two phase III trials published to check the superiority of TheraSphere Y90 radioembolization (RE) over standard systemic therapy with sorafenib in advanced HCC. These include the SARAH trial and the SIRveNIB trial. The median OS in the SARAH trial (conducted in 25 centers, France) was 8.0 months in the RE group $(\mathrm{n}=237)$ and 9.9 months in the sorafenib group $(\mathrm{n}=222){ }^{101}$ The median OS in the SIRveNIB trial (11 countries of Asia Pacific region) was 11.3 months in the $\mathrm{RE}(\mathrm{n}=182)$ and 10.4 months in the sorafenib $(\mathrm{n}=178)$ group. Although the tumor response rate was higher and the rate of serious adverse events was less in the RE group than the sorafenib group ( $20 \%$ versus $35 \%$, respectively), the disease control rate, progression free survival, and patient's health-related quality-of-life (HRQoL) was essentially similar among both groups. ${ }^{102}$

One prospective study to compare the efficacy of combining SORAfenib with local MICro-therapy guided by the gadolinium enhanced MRI named (SORAMIC) in advanced HCC patients concluded that addition of SIRT was safe but does not improve OS (14 months versus 11.1 months, respectively, in per protocol population, the SIRT plus sorafenib $(n=114)$ versus sorafenib group $(n=174) .{ }^{103}$

A few studies comparing SIRT to sorafenib in HCC with portal invasion found median OS benefits and preservation of HRQoL in these patients. ${ }^{104,105}$ In a retrospective comparative study, the median OS in patients treated with SIRT versus sorafenib were 26.2 


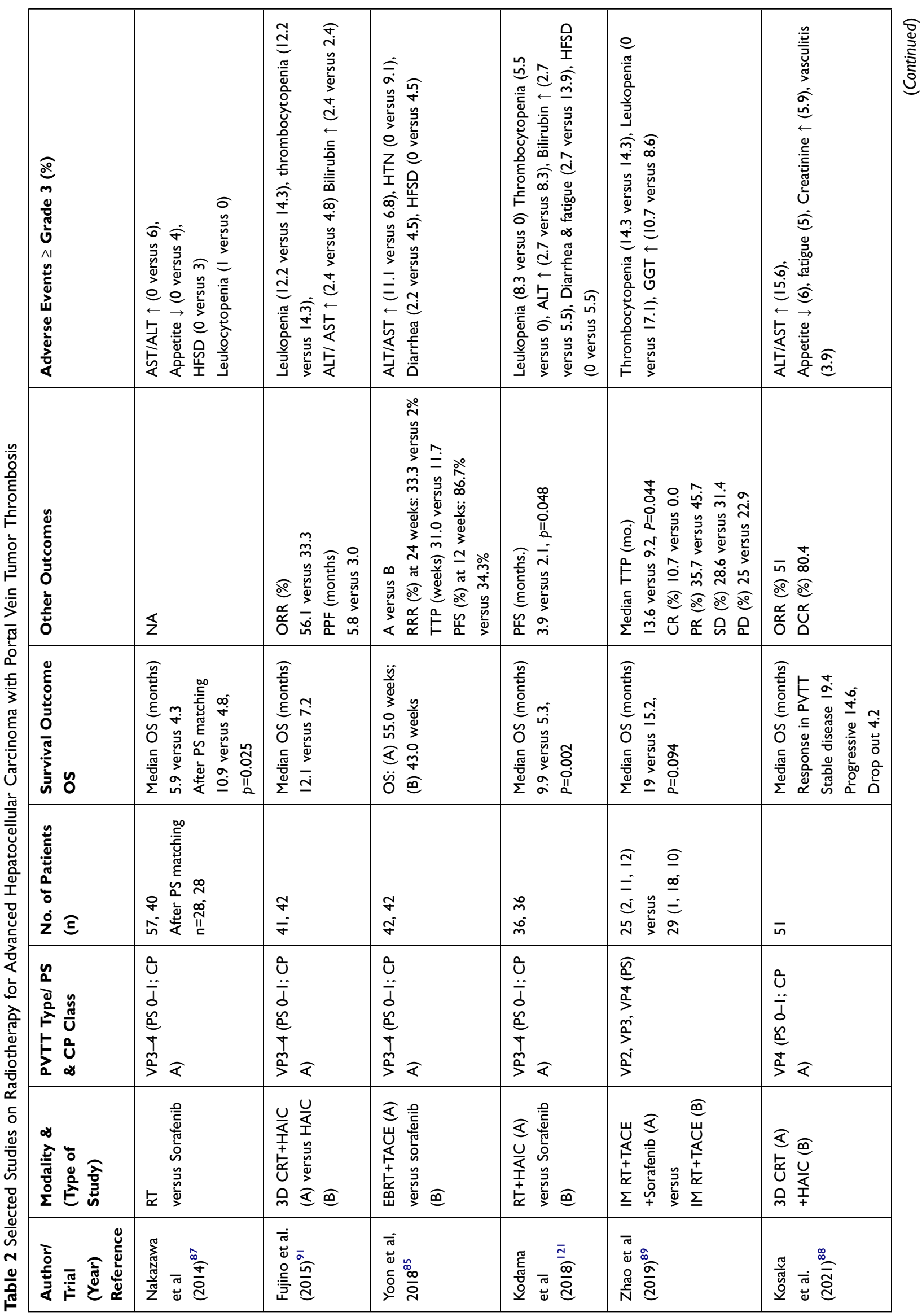




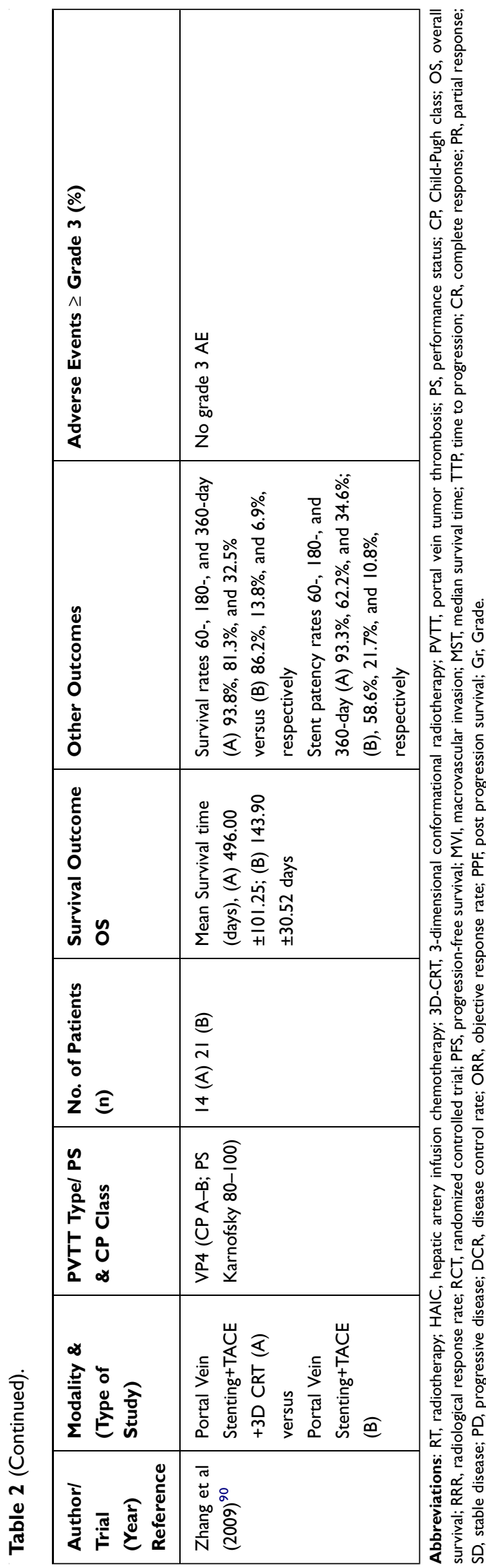

months versus 8.7 months, respectively. This difference was more marked in patients with VP1-3 versus VP4. The median OS in VP1-3 patients treated with SIRT was 25.3 months versus 7.0 months in the sorafenib group; and in VP4 patients it was 12.0 months with SIRT versus 6.5 months in the sorafenib group. ${ }^{104,105}$

Recently a study reported the local (tumor microenvironment) and systemic (blood) immune activation role of Y90-RE in the tumor microenvironment among the HCC patients treated with TARE. ${ }^{106}$ The clinical impact of personalized SPECT/CT-based dosimetry in HCC patients with PVTT treated with Y90 loaded glass microspheres has shown optimistic results. ${ }^{107}$ However, there is still a lack of high-level evidence to use SIRT in HCC patients and its effects need to be verified further in large RCTs.

\section{Hepatic Arterial Infusion Chemotherapy (HAIC)}

The delivery of chemotherapeutic agents via an hepatic arterial infusion chemotherapy (HAIC) approach directly transports the drugs into the tumor-feeding arteries and limits the systemic toxicity as well. ${ }^{108}$ It is proposed in many studies that HAIC yields an expressively higher response rate than systemic chemotherapy or sorafenib and among TACE refractory cases. ${ }^{109-112}$

Similar longer survival was reported by the Liver Cancer Study Group of Japan, using HAIC containing fine-powder cisplatin (New-FP) suspended in lipiodol and 5-FU in HCC patients with macrovascular invasion (MVI). The median survival time (MST) after propensity score was 15 months versus 7.9 months for the New-FP $(\mathrm{n}=442)$ and sorafenib groups $(\mathrm{n}=149)$, respectively $(P<0.001) .{ }^{113}$ Similarly, HAIC with low dose 5-FU and cisplatin (LFP) as a first-line treatment for HCC patients with PVTT (VP3, VP4) has also been proposed while switching to sorafenib if no response is observed. ${ }^{114-116}$ The survival time in the HAIC $(n=32)$ group was significantly longer versus the sorafenib $(\mathrm{n}=14)$ groups (309 days vs 120 days). ${ }^{116}$ Similar promising results with acceptable safety of combining HAIC with sorafenib were reported in multiple studies. ${ }^{117-119}$

A phase III RCT reported the survival benefits and safety of a combination of sorafenib and HAIC (low dose cisplatin and 5-fluorouracil (5-FU) over sorafenib alone among advanced HCC patients (SILIUS trial). ${ }^{118}$ The median OS among patients receiving sorafenib plus 
HAIC versus sorafenib alone were as follows: No vascular invasion group, 11.3 versus 11.9 months; VP1-3 group, 11.3 versus 14.4 months, respectively; while in the VP4 group (main portal invasion) it was 11.4 and 6.5 months, respectively. This trial identified HCC with VP4 patients as a potential group that can have extra OS benefit with this approach. ${ }^{118}$

Recently a multicenter randomized, open label, phase III clinical trial reported survival benefits of combining sorafenib with HAIC (SoraHAIC) containing 5-FU, leucovorin, and oxaliplatin (FOLFOX) among HCC patients with portal vein invasion. The reported median OS in the SoraHAIC group $(n=247)$ was 13.37 months $(95 \%$ $\mathrm{CI}=10.27-16.46$ ), while in the sorafenib group it was 7.13 months $(95 \% \mathrm{CI}=6.28-7.98)$ (hazard ratio $[\mathrm{HR}]$ $=0.35 ; 95 \% \mathrm{CI}=0.26-0.48 ; P<0.001) .{ }^{119}$ Another retrospective comparative study reported a longer OS (14 months) in HCC patients with PVTT receiving HAI pump of cisplatin and 5-FU when compared to the sorafenib group ( $\mathrm{OS}=7$ months). ${ }^{120}$

As neither of these treatments (sorafenib and HAIF) as monotherapy reasonably prolongs the survival, it is imperative to engage the tumor with more than one treatment option to improve OS. As the progressive involvement of the portal vein will eventually reduce the blood flow and further deteriorate the liver function, it seems appropriate to employ a treatment that has robust tumor thrombus downstaging effects. The consensus-based guidelines from Japan and Taiwan recommend HAIC as one of the treatment options for type VP3 and VP4 PVTT. $^{31,34}$

The combination of HAIC with RT has also been reported to significantly prolong OS and PFS better as compared to sorafenib alone among HCC with VP4 PVTT (median, 9.9 versus 5.3, and 3.9 versus 1.9 months). ${ }^{121}$ Recently combining HAIC with TACE and Sorafenib proved to be a safe and better treatment option for patients with PVTT, ${ }^{122}$ while addition of anti-PD-1 immunotherapy was reported to improve the efficacy of HAIC in advanced $\mathrm{HCC}^{123}$ (Table 3 ).

\section{Transarterial Chemoembolization}

The history of utilizing the TACE approach dates back to 1970s when anti-cancer drugs were delivered via a catheter in the vessels and later on gelatin sponge particles were used to embolize and treat inoperable HCC patients in Japan. ${ }^{124-126}$ Later on, the usage of lipiodol (an oil-based radio-opaque agent) improved therapeutic results and is still in practice now. ${ }^{127}$

There are two types of TACE techniques in practice. In conventional TACE, lipiodol delivers the cytotoxic agents directly to the tumor via intra-arterial injection. This is followed by the placement of embolic agents like a gelatin sponge. After the procedure, images are taken to look for the retention of lipiodol at the desired place, which allows prediction of the treatment achievement. The other one utilizes microsphere beads that contain cytotoxic drugs that are released in a sustained manner. As these beads are non-absorbable, they also act as an embolic sphere at the same time. The efficacy of both of these techniques is similar in terms of tumor response, time to progression, or OS, and in respect to safety endpoints. ${ }^{128-131}$

TACE is considered an effective palliative treatment for advanced HCC cases and has also been recommended as the treatment of choice in various guidelines. ${ }^{30-34,132}$ Recently, a multi-region (14 countries), multicenter (42 sites), large scale (number of patients $=18,031$ ), longitudinal cohort (the BRIDGE study) published data stating the most common BCLC stage at diagnosis to be Stage $\mathrm{C}$ in North America, Europe, China, and South Korea, and Stage A in Taiwan and Japan. The most frequent first treatment given across all the stages was TACE in North America, Europe, China, and South Korea, percutaneous ethanol injection or radiofrequency ablation in Japan, and resection in Taiwan. Rather than sorafenib, TACE and resection were the most frequent first recorded treatments for patients with BCLC stage $\mathrm{C}$ disease. This study gave a better understanding of the global HCC therapy and its clinical outcomes across real world clinical practice. ${ }^{133}$

The combination of systemic therapy and TACE has recently been reported to be safe and further improve outcomes in advanced HCC cases (BCLC C). ${ }^{134-136}$ The MST in Type I PVTT patients receiving a combination of TACE and sorafenib $(n=46)$ versus sorafenib $(n=45)$ was 15 months and 10 months, respectively. While in Type II, it was 13 months and 6 months respectively. The extent of the thrombus and selection of the therapy were independent prognostic factors for OS. This approach of confining the local tumor with TACE and systemic disease with sorafenib yields superior survival rates than either of these therapies alone. ${ }^{134,137}$ Recently, the combination of lenvatinib with TACE has also been reported to be safe in the setting of VP1-4 PVTT. ${ }^{138}$ The blending of RT with the TACE has been reported to increase the binding of 


\begin{tabular}{|c|c|c|c|c|c|c|}
\hline 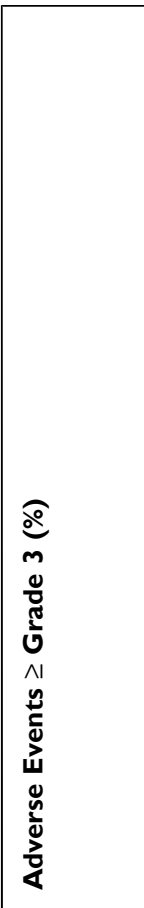 & 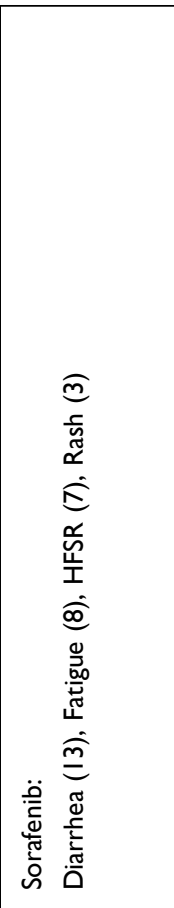 & 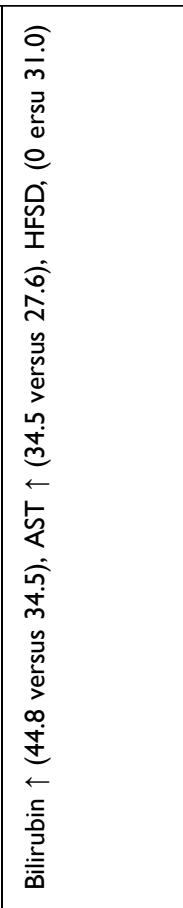 & 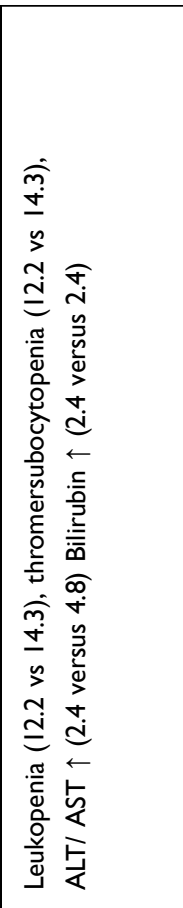 & 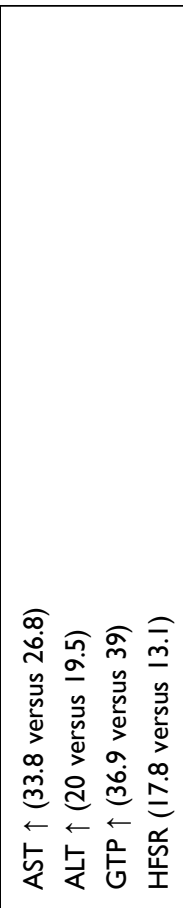 & 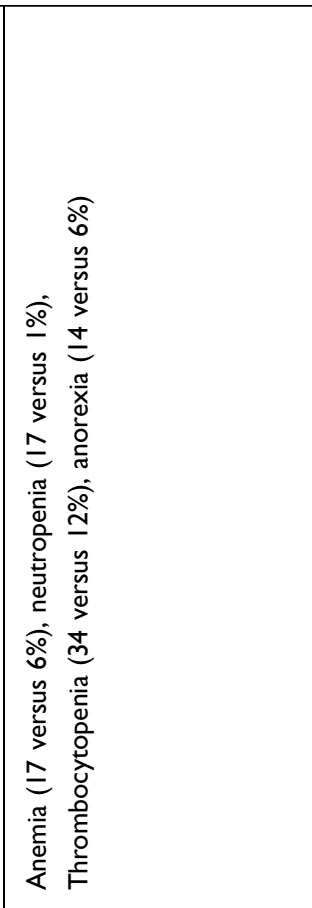 & 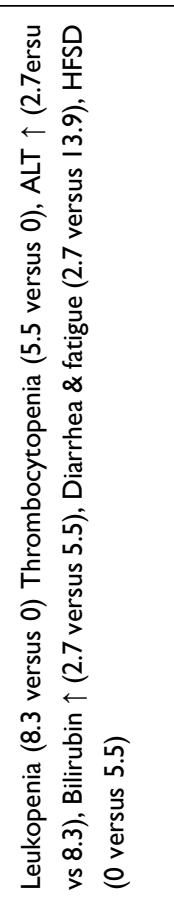 \\
\hline 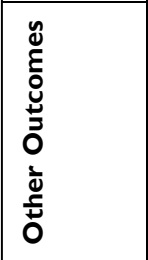 & 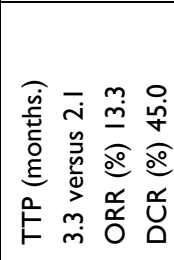 & 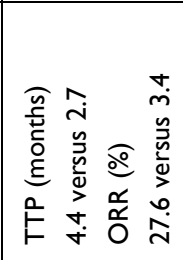 & 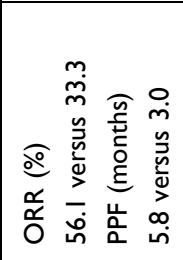 & 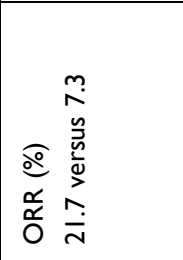 & 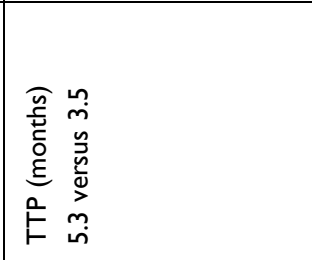 & 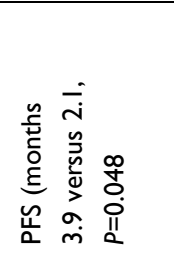 \\
\hline 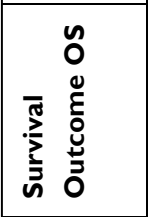 & 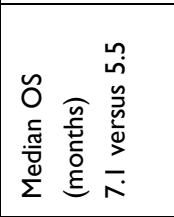 & 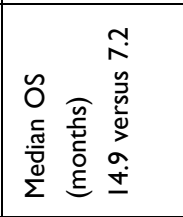 & 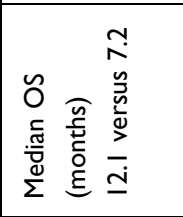 & 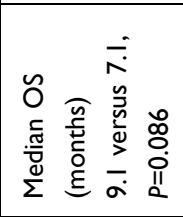 & 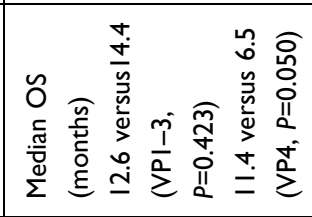 & 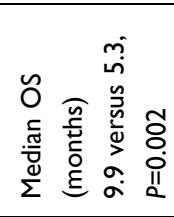 \\
\hline 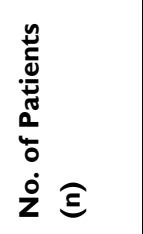 & 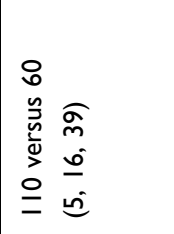 & $\begin{array}{l}\text { वे } \\
\text { oे }\end{array}$ & $\begin{array}{l}\mathcal{F} \\
\dot{\vec{\alpha}}\end{array}$ & 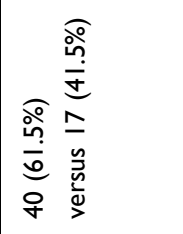 & 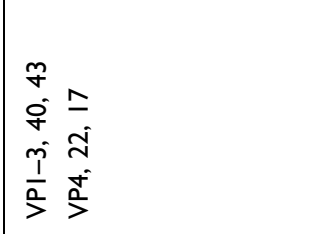 & $\begin{array}{l}\stackrel{\infty}{ } \\
\stackrel{m}{0}\end{array}$ \\
\hline 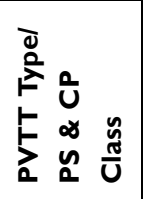 & 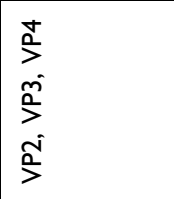 & 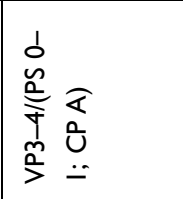 & 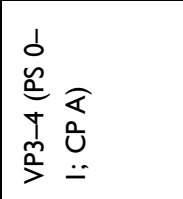 & 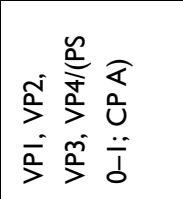 & 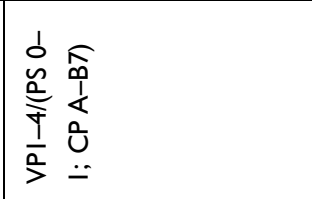 & 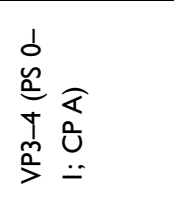 \\
\hline 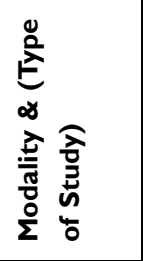 & 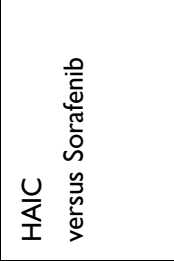 & 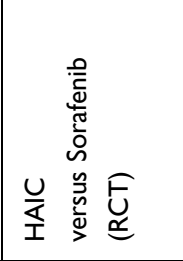 & 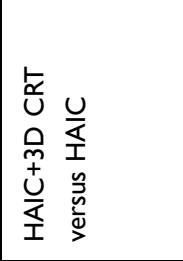 & 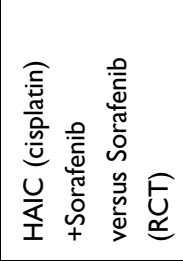 & 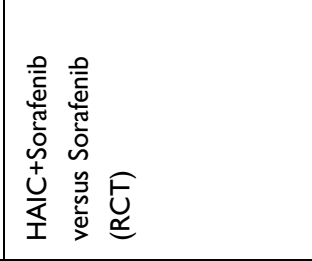 & 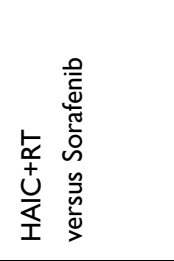 \\
\hline 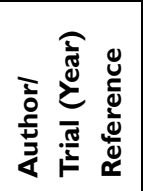 & 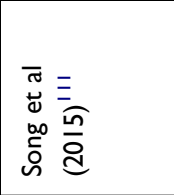 & 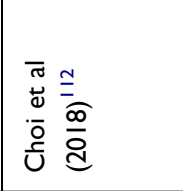 & 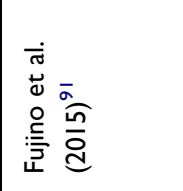 & 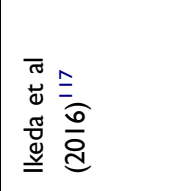 & 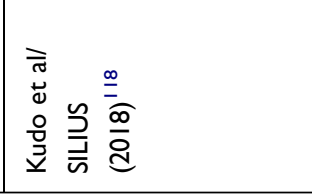 & 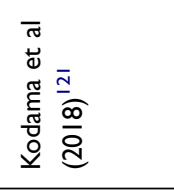 \\
\hline
\end{tabular}




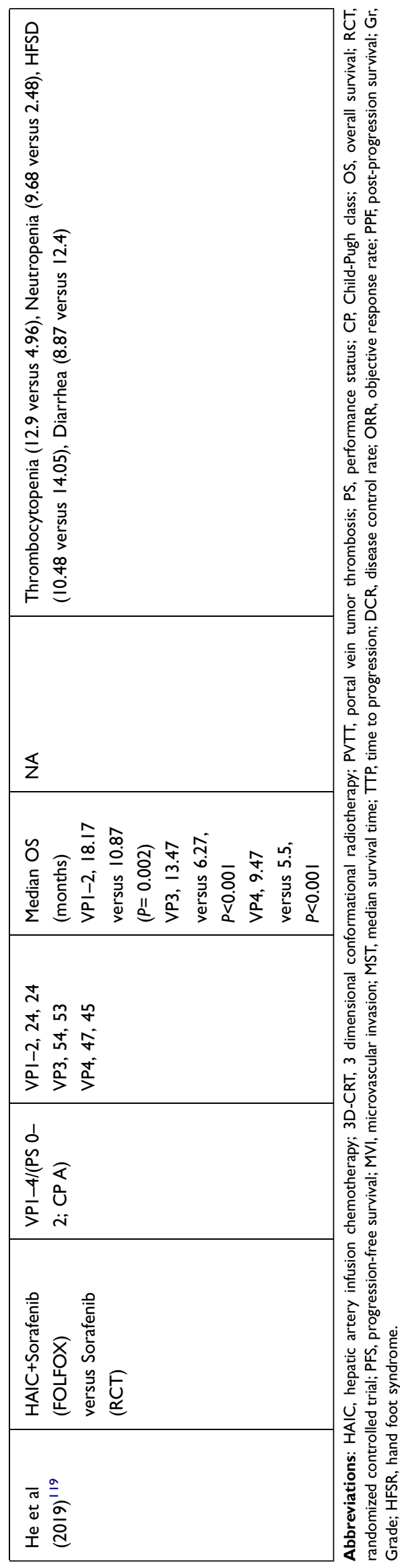

drugs used in the chemoembolization and thus these patients require a lower number of TACE sessions. ${ }^{92,95}$

The main portal vein trunk involvement (VP4) by HCC raises the portal vein pressure and the risk of tumor spread. Placing a stent in the portal vein can re-establish channel and blood flow. Besides placing therapeutic drugs through this conduit, this can also serve the purpose of carrying endovascular therapy. A number of studies have reported survival benefits of this strategy in selected HCC patients with VP4 PVTT as compared to a combination of TACE and sorafenib. The survival rate at 6-, 12-, and 24-month $\mathrm{s}$ was $88.9 \%, 54.3 \%$, and $14.1 \%$, respectively, among patients who also received stent along with placement of 125I seed, TACE, and sorafenib $(\mathrm{n}=37)$, while it was $45.8 \%, 0 \%$, and $0 \%$, respectively, among the patients getting TACE and sorafenib. As the flow in the main portal vein was restored via stenting, the TACE implication did not result in deterioration of liver functions. ${ }^{139-141}$ Likewise, a study reported better OS with the addition of RT to TACE versus either TACE or sorafenib alone ${ }^{142}$ (Table 4).

Also the combination of DEB-TACE with microsphere in HCC patients with PVTT has been reported safe, well tolerated and with promising preliminary clinical outcomes (the survival rate at $6,12,18$, and 24 months was $72.4, \% 41.4 \%, 22.4 \%$, and $19 \%$, respectively). ${ }^{143}$

\section{Surgical Methods: Efficacy of Different Methods}

One of the initial studies to report resection of HCC with PVTT dates back to the early 1980 s by Yamaoka et al. ${ }^{144}$ Initially tumor thrombectomy was performed to restore portal flow and allow transcatheter arterial embolization. Later on, thrombectomy combined with hepatectomy $(n=27)$, an emergency measure to manage the complications of portal hypertension, was performed. This approach unexpectedly produced better survival rates at 1 year $(52.2 \%), 2$ years $(23.2 \%)$, and 3 years $(11.6 \%)$, which were significantly higher than in those HCC patients who were not operated on $(n=22)$. About half the patients had survival $>1$ year in that series with the longest survivor reported $>4$ years. ${ }^{144}$

It was suggested that the OS of HCC patients with PVTT can be prolonged by vigilant selection criteria and by adopting the thrombectomy first technique. The criteria states patients with a primary lesion that can be resected while leaving a sufficient portion of liver and with no 


\begin{tabular}{|c|c|c|c|c|c|}
\hline 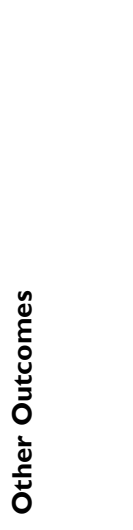 & 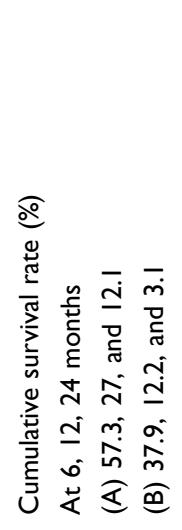 & 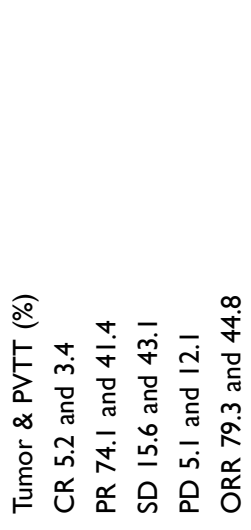 & 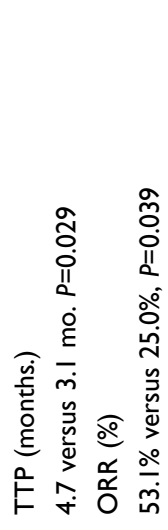 & 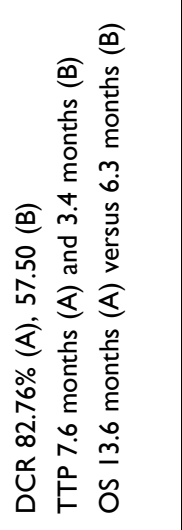 & 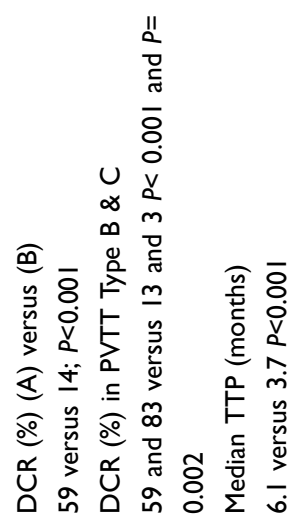 \\
\hline 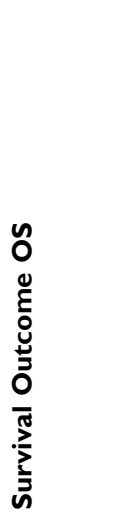 & 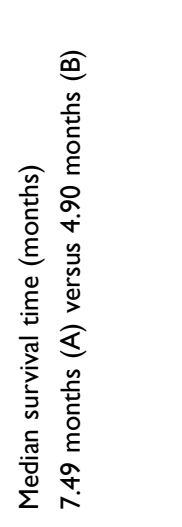 & 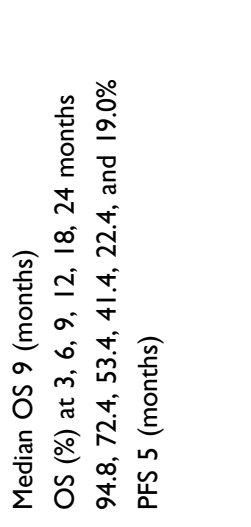 & $\S$ & 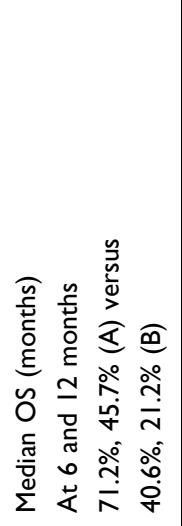 & 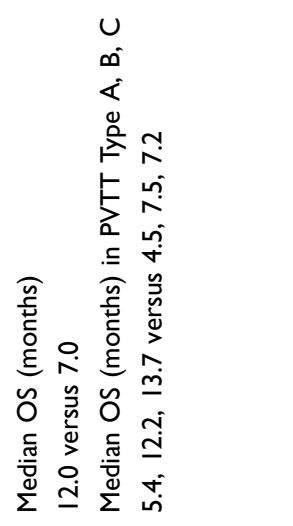 \\
\hline 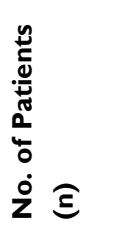 & 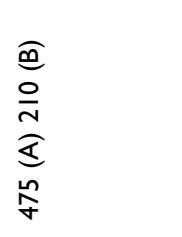 & $\stackrel{\infty}{\circ}$ & 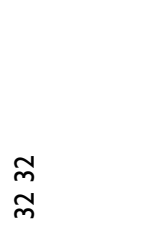 & 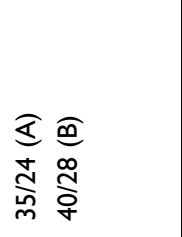 & $\frac{m}{\frac{m}{\infty}}$ \\
\hline 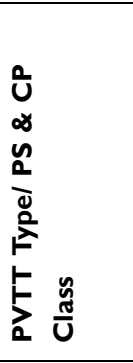 & 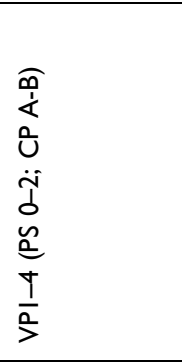 & 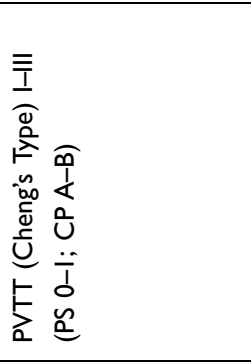 & $\frac{I}{0}$ & 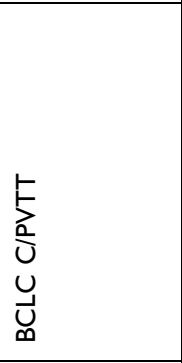 & 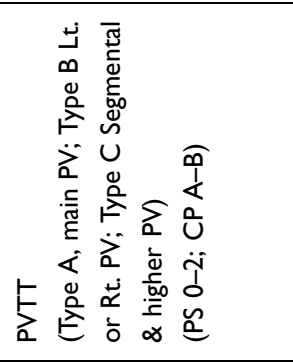 \\
\hline 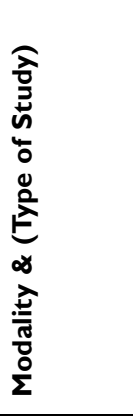 & 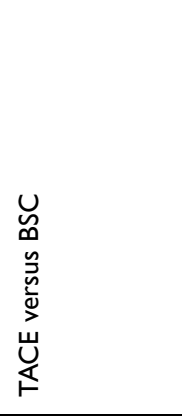 & 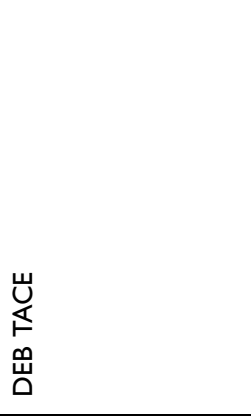 & 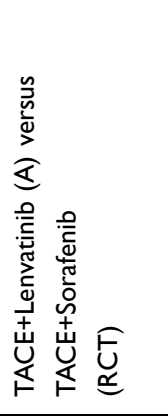 & 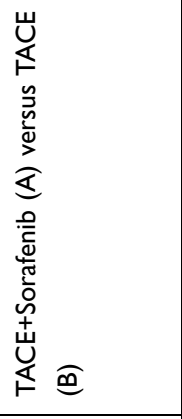 & 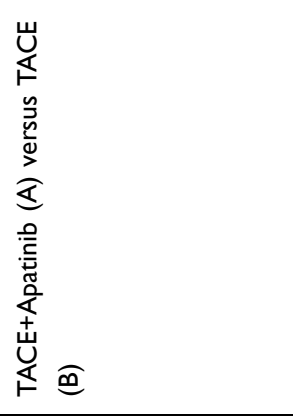 \\
\hline 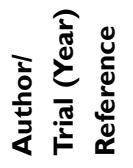 & $\begin{array}{l}\frac{\tilde{m}}{\widehat{o}} \\
\frac{0}{d} \\
\geq\end{array}$ & 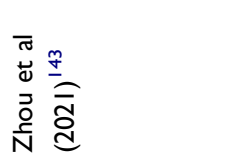 & 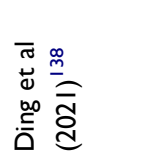 & 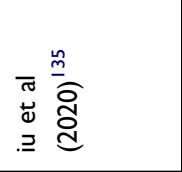 & 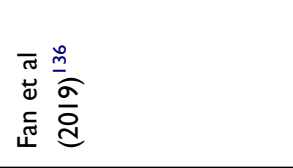 \\
\hline
\end{tabular}




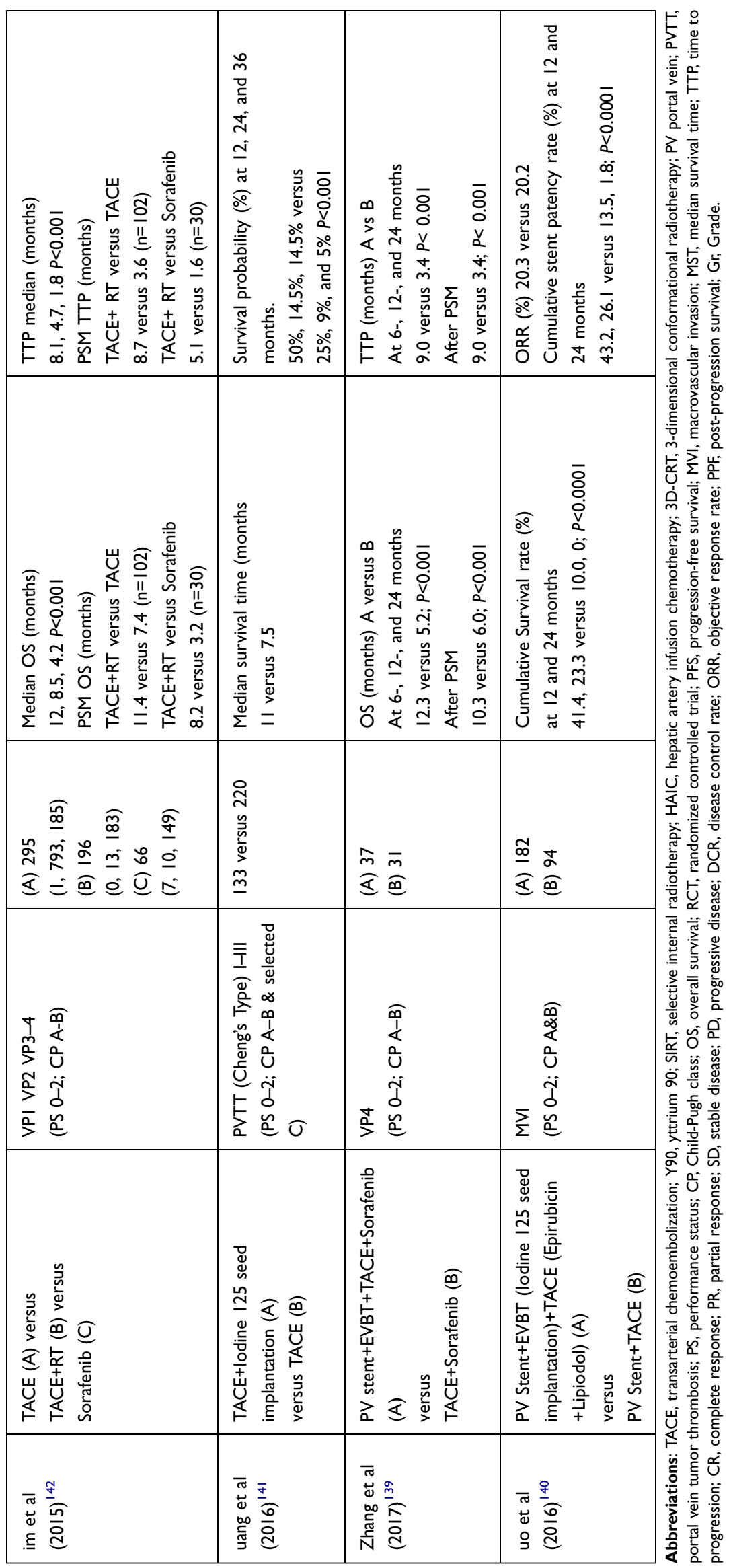


distant metastasis and clinically $\mathrm{CP}$ class $\mathrm{A}-\mathrm{B}$ and PS score $0-2$ (ECOG) to be eligible for resection. ${ }^{145}$

\section{Surgery - Liver Resection}

Several studies have reported improved clinical outcomes with surgical resection (hepatectomy along with thrombectomy) in selected HCC patients with PVTT. ${ }^{146-150}$ Performing resection on ailing liver in patients with advanced disease is technically demanding and not without risks. Although the selection of the treatment modality plays a significant role, it's also imperative to know that vessel involvement itself has a central role in possible progression and prognosis of the HCC in these patients. $^{49,151}$

A nation-wide survey by the Liver Cancer Study Group of Japan reported survival benefits for LR in HCC patient with PVTT. ${ }^{152}$ Patients were divided into a LR group $(n=2,093)$ and a non-LR group (received treatment TACE, ablation, chemotherapy, BSC, and other treatments). The patients were matched $(n=1,058$ in each group) using propensity score to confirm the survival benefit of LR. The MST suggests longer survival outcome with LR than non-surgical treatment: VP1, 4.13 years (95\% CI $=3.40-5.81)$; VP2, 2.49 years $(95 \% \mathrm{CI}=1.92$ $-3.08)$; VP3, 1.58 years $(95 \% \mathrm{CI}=1.22-2.17)$; and VP4, 0.91 years $(95 \% \mathrm{CI}=0.75-1.23)$. But the survival benefit of LR in the VP4 patients' group was not statistically significant. The most frequent site of recurrence was the liver for all extents of PVTT. The risk factors for OS after LR were liver cirrhosis, VP4, tumor size, tumor number $>3$, R2 resection, and AFP $\geq 15 \mathrm{ng} / \mathrm{mL} .{ }^{152}$ Liver resection is acceptable only in selected HCC patients with VP1-2 PVTT, while resection only is reported controversial in VP3-3 PVTT. ${ }^{145,153}$

A recent nationwide study from China reported a number of factors of long-term survival (LTS defined as 3 years) in HCC patients with VP1-3 PVTT who underwent LR $(\mathrm{n}=1,461) .{ }^{154}$ All suitable patients received adjuvant TACE at 1-month, none received any neoadjuvant therapy. The patients who underwent R0 resection, with intraoperative blood loss $\leq 400 \mathrm{~mL}$, TBIL $\leq 17.1 \mu \mathrm{mol} / \mathrm{L}$, and AFP $\leq 400 \mathrm{ng} / \mathrm{mL}$, had significantly longer OS and RFS than their counterparts (all $P<0.001$ ). About half of LTS received adjuvant TACE which was a significant predictor of OS and RFS (all $P<0.001$ ). Those who underwent major hepatectomy had significantly better RFS $(P=0.005)$ but similar OS $(P=0.0052)$. In addition, tumor diameter $>5 \mathrm{~cm}$, liver cirrhosis, and type VP4 PVTT were associated with poor OS and RFS. ${ }^{154}$ The extent of the involvement of the portal vein, size of the tumor $>7 \mathrm{~cm}$, and AFP levels $>30 \mathrm{ng} / \mathrm{mL}$ were reported independent prognostic factors for survival among patients who underwent liver resection for PVTT. ${ }^{153,155}$

One study proposed the surgical resection as a standard therapy for HCC patients with VP4 PVTT $(n=78)$. A prognostic index (PI) based on the presence of ascites, prothrombin activity, and maximal tumor diameter (prognostic factors with similar hazard ratio) was developed to help devise a treatment strategy. The PI is calculated as follows: Ascites (absent $=0$, present $=1)+(\mathrm{PT}$ activity: $\leq 75 \%=0, \geq 75 \%=1)+($ maximal tumor diameter: $<5 \mathrm{~cm}=0$, $\geq 5 \mathrm{~cm}=1$ ). MST for patients with PI 0, 1, 2, and 3 was 5.6-, 1.6-, 0.5-, and 0.1-year, respectively, and the 5-year survival rate was $51.9 \%, 10.3 \%, 0 \%$ and $0 \%$, respectively ${ }^{156,157}$ (Table 5).

A systemic review containing 29 studies from East Asia, Europe, and the USA reported OS benefit for LR in the advanced stage HCC patients with MVI $(n=3,659) .{ }^{146}$ The majority of the patients were CP class A (93\%) and the rest were CP class B. The MST was 15 months (range $=5.4-33$ months). The 3- and 5-year OS were $33 \%$ (range $=16-75 \%$ ) and $20 \%$ (range $=5-57 \%$ ), respectively, reported by 12 studies. The 3- and 5-year DFS were low at $16 \%$ (range $=4-60 \%$ ) and $16 \%$ (range $=0-33 \%$ ), respectively, reported by 12 studies. The median 5-year survival for VP1-2 patients was $45 \%$ (range $=25-54 \%$; reported by five studies). The median 5-year survival for patients with VP3 PVTT was 19\% (range $=0-38 \%$; reported by six studies). The median survival was $14.5 \%$ (range $=0-26.4 \%$; reported by 10 studies). The 5-year OS in the studies from the west $(n=4)$ and the USA $(\mathrm{n}=1)$ was comparable to 5 -year OS in the study, $14-20 \%$ versus $20 \%$, respectively. The $\mathrm{R} 0$ resection was obtained in $47-97 \%$ (median $=84 \%$; reported by 11 studies). In the median follow-up of 25 months, the median recurrence was high, at $80 \%$ (range $=28.5-88 \%$ ) (reported by 11 studies). This concluded significantly better OS with LR versus systemic therapy alone in type VP1 and VP2 and selected VP3HCC with PVTT patients, and that the extent of PVTT effect survival and results are better when the thrombus is located in distal PV branches (VP1-2). ${ }^{146}$

In the light of recent emerging data, surgical resection can be considered safe in carefully selected HCC cases with VP1-2 PVTT. ${ }^{158-161}$ 


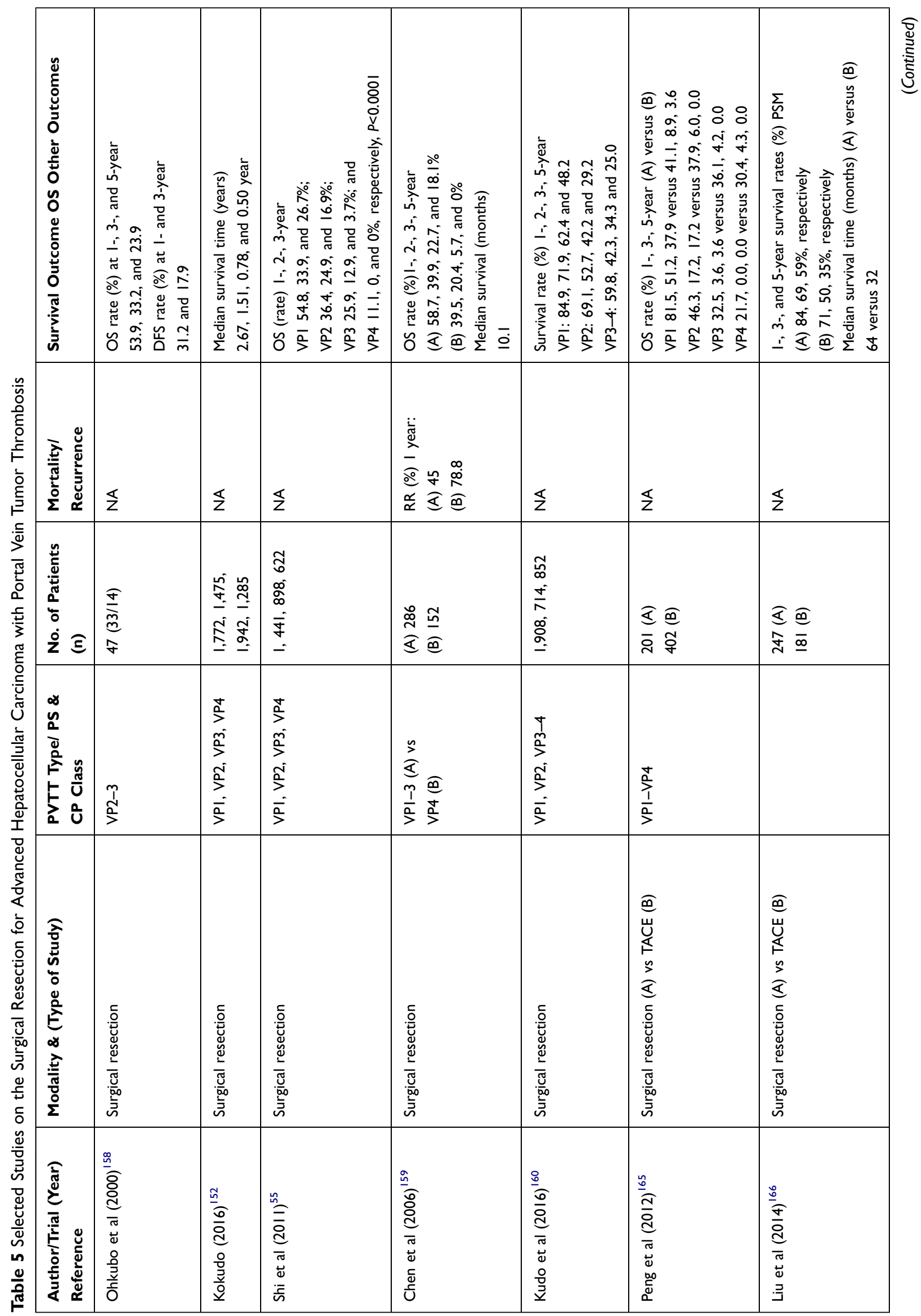




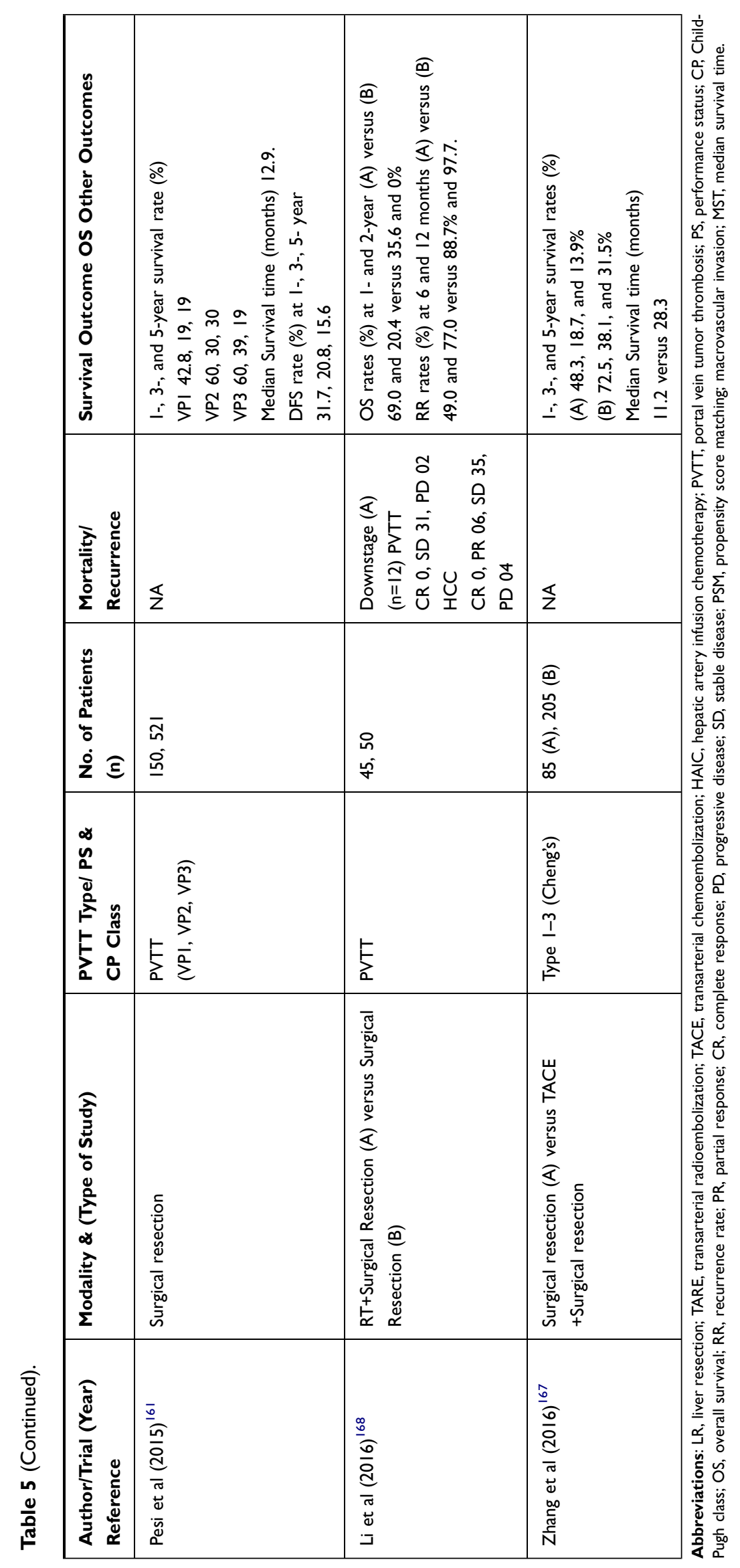


A meta-analysis containing 11 studies $(n=3,129)$ reported survival benefits of LR over TACE alone among HCC patients with PVTT. The OS rates at 1, 2, 3, and 5 years favor LR over TACE for type I and type II PVTT. But for type III PVTT, OS rates at 1, 2, 3, and 5 years were the same for both treatments. ${ }^{162}$ Similarly, a meta-analysis of 18 high quality studies $(n=5,986)$ reported significant OS benefits with LR compared to TACE in BCLC B and C groups. ${ }^{163}$

\section{Surgery Plus Adjuvant and Neoadjuvant Therapy}

Many studies have demonstrated the survival benefit of TACE in the adjuvant and neoadjuvant settings with acceptable safety among the patients at a high recurrence risk. ${ }^{164-167}$ Likewise, adjuvant RT as well as neoadjuvant 3D CRT along with HAIC has also been reported to play a downstaging role and further improve outcomes with surgical resection. ${ }^{168-170}$ As performing surgical resection takes out the major disease burden, the rationale behind using neoadjuvant and adjuvant therapy is that these take care of the micro foci that are left behind during surgery, the micro-metastasis not seen on the imaging and the dissociated cancer cells that are ambulated at the time of surgery.

A recent prospective comparative study showed better OS among HCC patients with type I-II PVTT who underwent TACE before LR over patients having LR alone (OS rate at 1-, 3-, and 5-year $=72.5 \%, 38.1 \%$, and $31.5 \%$ versus $48.3 \%, 18.7 \%$, and $13.9 \%$, respectively, and MST=28.3 months versus 11.2 months, respectively). However, there was no survival benefit of adding neoadjuvant TACE among HCC patients with type III PVTT. ${ }^{167}$

A recent systemic review and meta-analysis containing 24 studies ( $\mathrm{RCT}=9$; NRCT $=15 ; \mathrm{n}=6,977$ ) demonstrated that adjuvant TACE was associated with a better OS (based on $\mathrm{n}=6,573$; $\mathrm{RCT}=6$; $\mathrm{NRCT}=15$ ) and better DFS (based on $\mathrm{n}=2,260$; RCT $=7$; NRCT $=6$ ) than $\mathrm{LR}$ alone for HCC patients. ${ }^{171}$ In subgroup analyses, the pooled results revealed that adjuvant TACE was associated with an improved OS and DFS in the patients with multinodular HCC $(\mathrm{HR}=0.79$ and 0.31 , both $P<0.01)$, MVI $(\mathrm{HR}=0.62$ and 0.67 , both $\mathrm{P}<0.01$ ), or PVTT $(\mathrm{HR}=0.49$ and 0.58 , both $P<0.01$ ), but not among the patients with large HCC 5 $\mathrm{cm})$. Furthermore, the pooled analysis of all the studies demonstrated that patients who underwent surgery followed by adjuvant TACE had better 1-, 3-, and 5-year survival versus surgery alone. The pooled HR for OS and DFS for all studies was in favor of adjuvant TACE after surgical resection. ${ }^{171}$

A recent meta-analysis reported that sorafenib as adjuvant therapy after liver resection was associated with improved OS (hazard ratio $=0.71,95 \% \mathrm{CI}=0.59-0.86$; $P<0.001$ ), RFS (hazard ratio $=0.68,95 \% \mathrm{CI}=0.54-0.86$, $P=0.001$ ) and lower recurrence rate (pooled risk ratio $=0.78,95 \% \mathrm{CI}=0.68-0.90, P<0.001)$ without unbearable side-effects. ${ }^{172}$ The treatment options for the HCC patients with PVTT are listed in Figure 3.

Performing surgery in the form of liver resection along with thrombectomy reduces the tumor burden and portal pressure and its complications thus improve liver function and quality-of-life. ${ }^{173}$ Likewise, neoadjuvant therapy can achieve tumor downstaging, making surgery possible with improved DFS and OS while adjuvant therapy increases RFS.

\section{Transplantation}

There have been numerous criteria made to find the suitable HCC candidates for LT in order to increase OS and decrease the risk of recurrence. As there has been a trend in performing curative resections for the larger HCC lesions to render patients disease-free, likewise the selection criteria for LT are mounting the extent to include more HCC patients for curative intent. ${ }^{174,175}$ One of the studies (Bruix and colleagues) proposed that LT for HCC be performed when 5 years expected patient's survival is more than $50 \% .{ }^{176}$ When LT is being considered for patients outside the Milan Criteria it should be considered only when 5 years expected survival is no less than $61 \%$ (Volk et al). ${ }^{177}$

Considering the presence of PVTT in HCC patients and advanced disease much desired results cannot be achieved with LT in such patients. Although PVTT is generally considered a contraindication to LT, some centers have reported positive results for LT in the setting of gross vascular invasion in selected candidates. $\mathrm{Xu}$ et al suggested that living donor liver transplant (LDLT) can be considered an effective palliative treatment option in HCC patients with PVTT (VP4=10, VP3=14) and reported a 6-month, 1-year, and 2-year OS of $66.7 \%, 29.5 \%$, and $23.6 \%$, respectively. ${ }^{178}$ It should be realized that the intent of LT in this setting is not to cure but to prolong life by preventing the eminent complications of portal vein involvement. 


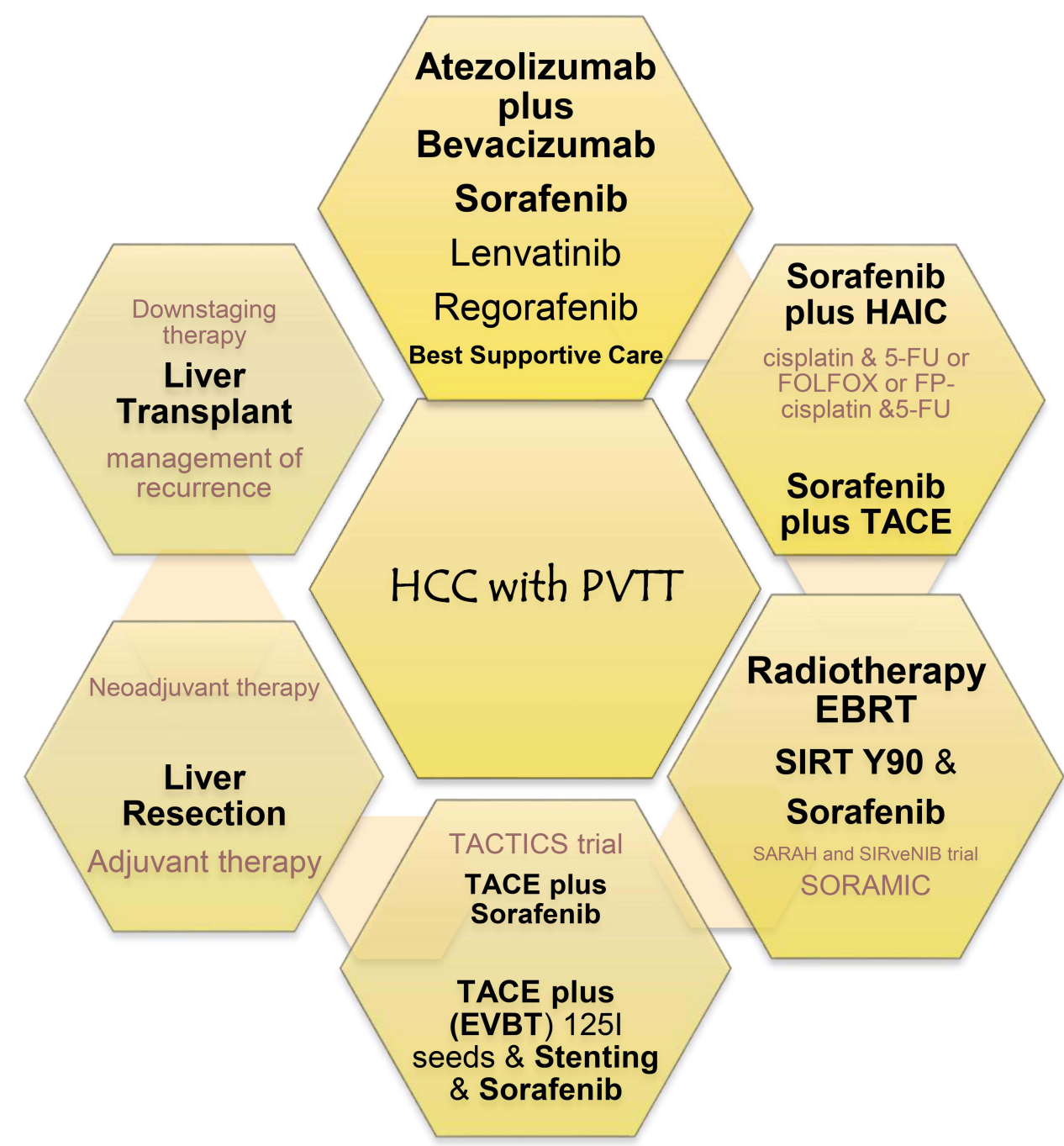

Figure 3 Therapeutic options for HCC patients with PVTT. There are several different treatment options available. Treatment plan for each patient should be personalized depending on performance status, stage, and the extent of involvement of the portal vein by the tumor thrombus, presence or absence of nodal disease, and distant metastasis. As combination therapy yields better results, the combination and the set of sequences largely remains unanswered and needs further prospective trials. Abbreviations: HCC, hepatocellular carcinoma; PVTT, portal vein tumor thrombus; HAIC, hepatic artery infusion chemotherapy; 5-FU, 5-fluorouracil. FOLFOX, fluorouracil, leucovorin and oxaliplatin; SIRT, selective internal radiation therapy; Y90, yttrium-90; TACE, transarterial chemoembolization. EBRT, External beam radiotherapy.

A study comparing DFS and OS rate in the PVTT (VP1-2) group ( $\mathrm{n}=34)$ and microvascular invasion group $(\mathrm{n}=24)$ who underwent LDLT suggested this as a valid treatment option as these outcomes did not differ significantly in the study $(63.9 \%$ and $50.3 \%$, respectively). However, the 1-, 3-, and 5-year DFS and OS rates in the PVTT VP3 group were poor $(28.6 \%, 14.3 \%$, and $14.3 \%$; and $71.4 \%, 14.3 \%$, and $14.3 \%$, respectively) and suggested LT a contraindication in this group. ${ }^{179} \mathrm{~A}$ recent study suggested LDLT a treatment option in selected HCC patients with PVTT (VP1-3). A "pre-LT AP score" based on the AFP x PIVKAII (pre-LT value) was presented stating a value of $<20,000 \mathrm{ng} / \mathrm{mL}$ a cut-off for better OS. One-, 3-, and 5-year OS were reported as
$72.7 \%, 63.6 \%$, and $63.6 \%$, respectively, and the RFS as $63.6 \%, 45.5 \%$, and $45.5 \%$, respectively. ${ }^{180}$

LT has also been reported to have significantly better outcomes than LR among HCC patients with VP1-2 PVTT. ${ }^{181,182}$ The median OS and RFS of LT versus LR in VP1-2 were more pronounced when the AFP levels were $>200 \mathrm{ng} / \mathrm{mL}$ (23.6 months versus 9.8 months and 18.0 months versus 2.1 months,respectively). Whereas type I PVTT patients had AFP $\leq 200$, the LT and LR achieved similar median RFS and OS (16.33 months versus 23.26 months and 36.47 months versus 36.17 months). Among patients with PVTT type II, no significant differences in RFS and OS were found between LT and LR. In the entire cohort comparing LT ( $n=47)$ vs LR $(n=47)$, RFS 
and OS rates at 3 -years were $39.1 \%$ and $45.7 \%$ and $13.5 \%$ and $28.1 \%$, respectively. ${ }^{182}$

The role of neoadjuvant downstaging therapy (DS) in various cancer types has been established, whereas studies on this approach in HCC patients with PVTT are limited in number and are small cohorts. The survival benefits of neoadjuvant locoregional therapy (TACE, Y90-RE, RFA, or a combination of these therapies) before LT in selected cases with advanced HCC stage III/IV (VP1-VP2) have been reported. ${ }^{183}$

The concurrent use of chemoradiotherapy (5-FU and RT-45 Gy over 5 weeks) and HAIC (5-FU/cisplatin) as DS modality was reported in a small cohort of HCC patients $(\mathrm{n}=8)$ with type VP3 and VP4 PVTT.96,97 The 1-year short-term DFS rate was $87.5 \%$. Similarly, TACE and RT have been demonstrated to be effective DS therapies in HCC patients $(n=17)$ with major vascular involvement before LDLT. One- and 3-year OS rates were $87.4 \%$ and $60.5 \%$, respectively, and DFS rates were $70.6 \%$ and $57.8 \%$, respectively. ${ }^{184}$ Liver directed neoadjuvant therapies appear to be a more effective DS strategy than others in advanced disease. Thus, in carefully selected HCC patients with VP1-2 PVTT the LDLT after neoadjuvant therapy may be considered an effective palliative treatment.

\section{Conclusion}

Portal vein involvement in HCC is considered an advanced stage and its severity is related with the prognosis. The survival outcomes with the use of single modality treatment are not satisfactory whereas the combination of various treatment options have stated significantly better results. This trend is also reflected in the recent guidelines from different regions on the management of HCC with PVTT. At present, the combination systemic therapy with atezolizumab plus bevacizumab is considered standard of care in advanced HCC cases. Through the refinement in drugs and delivery systems, locoregional therapy with TACE, HAIC, and EBRT are considered effective treatment options among VP1-2 PVTT patients. With the improvements in surgical techniques, liver resection is also considered a valid option in carefully selected HCC cases with VP1-2 PVTT. Data on the prospect of combining adjuvant as well as neoadjuvant therapies is evolving with some promising results. In highly selected HCC cases with VP1-2 PVTT, LDLT has also been reported to produce better OS and DFS compared to patients receiving conservative therapy. Considering PVTT as the high tumor burden state, neoadjuvant downstaging therapy must be an essential preliminary condition to decrease the recurrence rate. The most suitable treatment options for the patients with VP3-4 PVTT includes systemic therapy with atezolizumab plus bevacizumab, TARE, and RT. Given the added complexity of the disease, a multidisciplinary management employing all the potentially beneficial treatment modalities should be considered.

\section{Abbreviations}

HCC, hepatocellular carcinoma; PVTT, portal vein tumor thrombosis; TACE, transarterial chemoembolization; RT, radiotherapy; 3D CRT, three-dimensional conformational radiotherapy; SBRT, stereotactic body radiation therapy; EBRT, external beam radiotherapy; SIRT, selective internal radiotherapy; RE, radioembolization; TARE, transarterial radioembolization; IMRT, intermittent radiotherapy; HAIC, hepatic artery infusion chemotherapy; Y90, yttrium 90; LR, liver resection; LT, liver transplantation; LDLT, living donor liver transplantation; BSC, best supportive care; TT, tumor thrombus; EASL, European Association for Study of Liver; AASLD, American Association for the Study of Liver Diseases; AFP, alpha fetoprotein; PIVKAII, Protein Induced by Vitamin K absence or Antagonist-II; DCP, Des-gamma-Carboxy Prothrombin; OR, Odds ratio; HR, hazard risk; HBV, hepatitis B virus; HCV, hepatitis $\mathrm{C}$ virus; CECT, Contrast Enhanced Computed Tomography; SPECT, Single Photon Emission Computed Tomography; CP score, Child-Pugh Score; OS, overall survival; DFS, disease free survival; MST, median survival time; RFS, recurrence free survival; PSM, propensity score matching; PI, prognostic index; PSS, prognostic scoring system; BCLC, Barcelona Clinic Liver Cancer; PS, Performance status; FDA, Food and Drug Administration; HRQoL, Health-Related Quality-of-Life; RCT, randomized controlled trial; NRCT, non-randomized controlled trial.

\section{Funding}

This work was supported by the National Natural Science Funds for Distinguished Young Scholar of China (No. 81625003) and the Key Program, National Natural Science Foundation of China (No. 81930016).

\section{Disclosure}

The authors declare no conflicts of interest for this work. 


\section{References}

1. Sung H, Ferlay J, Siegel RL, et al. Global Cancer Statistics 2020: GLOBOCAN Estimates of Incidence and Mortality Worldwide for 36 Cancers in 185 Countries. CA Cancer J Clin. 2021;71 (3):209-249. doi:10.3322/caac.21660

2. Kudo M, Izumi N, Kubo S, et al. Report of the 20th Nationwide follow-up survey of primary liver cancer in Japan. Hepatol Res. 2020;50(1):15-46. doi:10.1111/hepr.13438

3. Cheung TK, Lai C-L, Wong BC-Y, et al. Clinical features, biochemical parameters, and virological profiles of patients with hepatocellular carcinoma in Hong Kong. Aliment Pharmacol Ther. 2006;24(4):573-583. doi:10.1111/j.13652036.2006.03029.x

4. Llovet JM, Bustamante J, Castells A, et al. Natural history of untreated nonsurgical hepatocellular carcinoma: rationale for the design and evaluation of therapeutic trials. Hepatology. 1999;29 (1):62-67. doi:10.1002/hep.510290145

5. Kwak HW, Park J-W, Nam B-H, et al. Clinical outcomes of a cohort series of patients with hepatocellular carcinoma in a hepatitis B virus-endemic area. J Gastroenterol Hepatol. 2014;29(4):820-829. doi:10.1111/jgh.12470

6. Kloeckner R, Maehringer-Kunz A, Dos Santos DP, et al. Portal vein tumor thrombosis has a direct impact on liver function. $J$ Hepatol. 2018;68:S209-S210. doi:10.1016/S0168-8278(18) 30633-0

7. Befeler AS, Di Bisceglie AM. Hepatocellular carcinoma: diagnosis and treatment. Gastroenterology. 2002;122(6):1609-1619. doi:10.1053/gast.2002.33411

8. Mendizabal M, Reddy KR. Current management of hepatocellular carcinoma. Med Clin North Am. 2009;93(4):885-900, viii. doi:10.1016/j.mena.2009.03.004

9. Bialecki ES, Di Bisceglie AM. Clinical presentation and natural course of hepatocellular carcinoma. Eur J Gastroenterol Hepatol. 2005;17(5):485-489. doi:10.1097/00042737-200505000-00003

10. European Association for the Study of the Liver. EASL Clinical Practice Guidelines: management of hepatocellular carcinoma. $J$ Hepatol. 2018;69(1):182-236.

11. Heimbach JK, Kulik LM, Finn RS, et al. AASLD guidelines for the treatment of hepatocellular carcinoma. Hepatology. 2018;67 (1):358-380. doi:10.1002/hep.29086

12. Llovet JM, Brú C, Bruix J. Prognosis of hepatocellular carcinoma: the BCLC staging classification. Semin Liver Dis. 1999;19(3):329-338. doi:10.1055/s-2007-1007122

13. Llovet JM, Ricci S, Mazzaferro V, et al. Sorafenib in advanced hepatocellular carcinoma. $N$ Engl J Med. 2008;359(4):378-390. doi:10.1056/NEJMoa0708857

14. Cheng AL, Kang Y-K, Chen Z, et al. Efficacy and safety of sorafenib in patients in the Asia-Pacific region with advanced hepatocellular carcinoma: a phase III randomised, double-blind, placebo-controlled trial. Lancet Oncol. 2009;10(1):25-34. doi:10.1016/S1470-2045(08)70285-7

15. Jeong SW, Jang JY, Shim KY, et al. Practical effect of sorafenib monotherapy on advanced hepatocellular carcinoma and portal vein tumor thrombosis. Gut Liver. 2013;7(6):696-703. doi:10.5009/gn1.2013.7.6.696

16. Vitale A, Peck-Radosavljevic M, Giannini EG, et al. Personalized treatment of patients with very early hepatocellular carcinoma. J Hepatol. 2017;66(2):412-423. doi:10.1016/j.jhep.2016.09.012

17. Giannini EG, Bucci L, Garuti F, et al. Patients with advanced hepatocellular carcinoma need a personalized management: a lesson from clinical practice. Hepatology. 2018;67 (5):1784-1796. doi:10.1002/hep.29668

18. Graf D, Vallböhmer D, Knoefel WT, et al. Multimodal treatment of hepatocellular carcinoma. Eur J Intern Med. 2014;25 (5):430-437. doi:10.1016/j.ejim.2014.03.001
19. Villanueva A. Hepatocellular Carcinoma. $N$ Engl $J$ Med. 2019;380(15):1450-1462. doi:10.1056/NEJMra1713263

20. Forner A, Reig M, Bruix J. Hepatocellular carcinoma. Lancet. 2018;391(10127):1301-1314. doi:10.1016/S0140-6736(18)30010-2

21. Forner A. Current strategy for staging and treatment: the BCLC update and future prospects. Semin Liver Dis. 2010;30(1):61-74. doi:10.1055/s-0030-1247133

22. Weinmann A, Koch S, Sprinzl M, et al. Survival analysis of proposed BCLC-B subgroups in hepatocellular carcinoma patients. Liver Int. 2015;35(2):591-600. doi:10.1111/liv.12696

23. Mazzaferro V, Llovet JM, Miceli R, et al. Predicting survival after liver transplantation in patients with hepatocellular carcinoma beyond the Milan criteria: a retrospective, exploratory analysis. Lancet Oncol. 2009;10(1):35-43. doi:10.1016/S1470-2045(08) 70284-5

24. Chung H, Kudo M, Takahashi S, et al. Comparison of three current staging systems for hepatocellular carcinoma: japan integrated staging score, new Barcelona Clinic Liver Cancer staging classification, and Tokyo score. J Gastroenterol Hepatol. 2008;23 (3):445-452. doi:10.1111/j.1440-1746.2007.05075.x

25. Chevret S, Trinchet J-C, Mathieu D, et al. A new prognostic classification for predicting survival in patients with hepatocellular carcinoma. Groupe d'Etude et de Traitement du Carcinome Hépatocellulaire. $J$ Hepatol. 1999;31(1):133-141. doi:10.1016/ S0168-8278(99)80173-1

26. Manghisi G, Elba S, Mossa A, et al. A new prognostic system for hepatocellular carcinoma: a retrospective study of 435 patients: the Cancer of the Liver Italian Program (CLIP) investigators. Hepatology. 1998;28(3):751-755. doi:10.1002/hep.510280322

27. Leung TW, Tang AMY, Zee B, et al. Construction of the Chinese University Prognostic Index for hepatocellular carcinoma and comparison with the TNM staging system, the Okuda staging system, and the Cancer of the Liver Italian Program staging system: a study based on 926 patients. Cancer. 2002;94 (6):1760-1769. doi:10.1002/cncr.10384

28. Yau T, Tang VYF, Yao T-J, et al. Development of Hong Kong Liver Cancer staging system with treatment stratification for patients with hepatocellular carcinoma. Gastroenterology. 2014;146(7):1691-700.e3. doi:10.1053/j.gastro.2014.02.032

29. Kitai S, Kudo M, Minami Y, et al. Validation of a new prognostic staging system for hepatocellular carcinoma: a comparison of the biomarker-combined Japan Integrated Staging Score, the conventional Japan Integrated Staging Score and the BALAD Score. Oncology. 2008;75(Suppl 1):83-90. doi:10.1159/000173428

30. Benson AB, D'Angelica MI, Abbott DE, et al. Guidelines Insights: hepatobiliary Cancers, Version 2.2019. J Natl Compr Canc Netw. 2019;17(4):302-310. doi:10.6004/jnccn.2019.0019

31. Kudo M, Kawamura Y, Hasegawa K, et al. Management of Hepatocellular Carcinoma in Japan: JSH Consensus Statements and Recommendations 2021 Update. Liver Cancer. 2021;10 (3):181-223. doi:10.1159/000514174

32. Zhou J, Sun H, Wang Z, et al. Guidelines for the Diagnosis and Treatment of Hepatocellular Carcinoma (2019 Edition). Liver Cancer. 2020;9(6):682-720. doi:10.1159/000509424

33. Korean Liver Cancer Association K, National Cancer Center N. 2018 Korean Liver Cancer Association-National Cancer Center Korea Practice Guidelines for the Management of Hepatocellular Carcinoma. Gut Liver. 2019;13(3):227-299. doi:10.5009/gnl19024

34. Lu SN, Wang JH, Su CW, et al. Management consensus guideline for hepatocellular carcinoma: 2016 updated by the Taiwan Liver Cancer Association and the Gastroenterological Society of Taiwan. J Formos Med Assoc. 2018;117(5):381-403.

35. Zucman-Rossi J, Villanueva A, Nault J-C, et al. Genetic Landscape and Biomarkers of Hepatocellular Carcinoma. Gastroenterology. 2015;149(5):1226-1239.e4. doi:10.1053/j. gastro.2015.05.061 
36. Chen C, Chen D-P, Gu -Y-Y, et al. Vascular invasion in hepatitis $\mathrm{B}$ virus-related hepatocellular carcinoma with underlying cirrhosis: possible associations with ascites and hepatitis B viral factors? Tumour Biol. 2015;36(8):6255-6263. doi:10.1007/ s13277-015-3311-8

37. Zhang H, Ye J, Weng X, et al. Comparative transcriptome analysis reveals that the extracellular matrix receptor interaction contributes to the venous metastases of hepatocellular carcinoma. Cancer Genet. 2015;208(10):482-491. doi:10.1016/j. cancergen.2015.06.002

38. Liu S, Guo W, Shi J, et al. MicroRNA-135a contributes to the development of portal vein tumor thrombus by promoting metastasis in hepatocellular carcinoma. J Hepatol. 2012;56(2):389-396. doi:10.1016/j.jhep.2011.08.008

39. Fan X, Li Y, Yi X, et al. Epigenome-wide DNA methylation profiling of portal vein tumor thrombosis (PVTT) tissues in hepatocellular carcinoma patients. Neoplasia. 2020;22 (11):630-643. doi:10.1016/j.neo.2020.09.007

40. Wang D, Zhu Y, Tang J, et al. Integrative molecular analysis of metastatic hepatocellular carcinoma. BMC Med Genomics. 2019;12(1):164. doi:10.1186/s12920-019-0586-4

41. Brodt P. Role of the Microenvironment in Liver Metastasis: from Pre- to Prometastatic Niches. Clin Cancer Res. 2016;22(24):5971. doi:10.1158/1078-0432.CCR-16-0460

42. Wei X, Li N, Li S, et al. Hepatitis B virus infection and active replication promote the formation of vascular invasion in hepatocellular carcinoma. BMC Cancer. 2017;17(1):304. doi:10.1186/ s12885-017-3293-6

43. Li Z. Association of Preoperative Antiviral Treatment With Incidences of Microvascular Invasion and Early Tumor Recurrence in Hepatitis B Virus-Related Hepatocellular Carcinoma. JAMA Surg. 2018;153(10):e182721. doi:10.1001/ jamasurg.2018.2721

44. Huang S, Xia Y, Lei Z, et al. Antiviral Therapy Inhibits Viral Reactivation and Improves Survival after Repeat Hepatectomy for Hepatitis B Virus-Related Recurrent Hepatocellular Carcinoma. J Am Coll Surg. 2017;224(3):283-293.e4. doi:10.1016/j. jamcollsurg.2016.11.009

45. Intagliata NM, Caldwell SH, Tripodi A. Diagnosis, Development, and Treatment of Portal Vein Thrombosis in Patients With and Without Cirrhosis. Gastroenterology. 2019;156(6):1582-1599.e1. doi:10.1053/j.gastro.2019.01.265

46. Valla DC, Condat B. Portal vein thrombosis in adults: pathophysiology, pathogenesis and management. J Hepatol. 2000;32 (5):865-871. doi:10.1016/S0168-8278(00)80259-7

47. Lim J, Kim HI, Kim E, et al. Variceal bleeding is aggravated by portal venous invasion of hepatocellular carcinoma: a matched nested case-control study. BMC Cancer. 2021;21(1):11. doi:10.1186/s12885-020-07708-1

48. Gon H, Kido M, Tanaka M, et al. Growth velocity of the portal vein tumor thrombus accelerated by its progression, alpha-fetoprotein level, and liver fibrosis stage in patients with hepatocellular carcinoma. Surgery. 2018;164(5):1014-1022. doi:10.1016/j.surg.2018.06.025

49. Guarino M, Cucchetti A, Pontillo G, et al. Pattern of macrovascular invasion in hepatocellular carcinoma. Eur $J$ Clin Invest. 2021;51(7):e13542. doi:10.1111/eci.13542

50. Pawarode A, Voravud N, Sriuranpong V, et al. Natural history of untreated primary hepatocellular carcinoma: a retrospective study of 157 patients. Am J Clin Oncol. 1998;21(4):386-391. doi:10.1097/00000421-199808000-00014

51. Xu JF. Surgical treatment for hepatocellular carcinoma with portal vein tumor thrombus: a novel classification. World J Surg Oncol. 2015;13:86. doi:10.1186/s12957-015-0493-x
52. Ikai I. Report of the 15th follow-up survey of primary liver cancer. Hepatol Res. 2004;28(1):21-29. doi:10.1016/j. hepres.2003.08.002

53. Ikai I, Arii S, Okazaki M, et al. Report of the 17th Nationwide Follow-up Survey of Primary Liver Cancer in Japan. Hepatol Res. 2007;37(9):676-691. doi:10.1111/j.1872-034X.2007.00119.x

54. Shuqun C. Tumor thrombus types influence the prognosis of hepatocellular carcinoma with the tumor thrombi in the portal vein. Hepatogastroenterology. 2007;54(74):499-502.

55. Shi J, Lai ECH, Li N, et al. A new classification for hepatocellular carcinoma with portal vein tumor thrombus. $J$ Hepatobiliary Pancreat Sci. 2011;18(1):74-80. doi:10.1007/s00534-010-0314-0

56. Tublin ME, Dodd GD 3rd, Baron RL. Benign and malignant portal vein thrombosis: differentiation by CT characteristics. AJR Am J Roentgenol. 1997;168(3):719-723. doi:10.2214/ajr.168.3.9057522

57. Tarantino L, Francica G, Sordelli I, et al. Diagnosis of benign and malignant portal vein thrombosis in cirrhotic patients with hepatocellular carcinoma: color Doppler US, contrast-enhanced US, and fine-needle biopsy. Abdom Imaging. 2006;31(5):537-544. doi:10.1007/s00261-005-0150-x

58. Canellas R, Mehrkhani F, Patino M, et al. Characterization of Portal Vein Thrombosis (Neoplastic Versus Bland) on CT Images Using Software-Based Texture Analysis and Thrombus Density (Hounsfield Units). AJR Am J Roentgenol. 2016;207(5):W81w87. doi:10.2214/AJR.15.15928

59. Hu S. The role of $18 \mathrm{~F}-\mathrm{FDG}$ PET/CT in differentiating malignant from benign portal vein thrombosis. Abdom Imaging. 2014;39 (6):1221-1227. doi:10.1007/s00261-014-0170-5

60. Spreafico C, Sposito C, Vaiani M, et al. Development of a prognostic score to predict response to Yttrium-90 radioembolization for hepatocellular carcinoma with portal vein invasion. J Hepatol. 2018;68(4):724-732. doi:10.1016/j.jhep.2017.12.026

61. Zhang X-P, Gao Y-Z, Chen Z-H, et al. An Eastern Hepatobiliary Surgery Hospital/Portal Vein Tumor Thrombus Scoring System as an Aid to Decision Making on Hepatectomy for Hepatocellular Carcinoma Patients With Portal Vein Tumor Thrombus: a Multicenter Study. Hepatology. 2019;69(5):2076-2090. doi:10.1002/hep.30490

62. Hwang S, Moon DB, Kim KH, et al. Prognostic Accuracy of the ADV Score Following Resection of Hepatocellular Carcinoma with Portal Vein Tumor Thrombosis. J Gastrointest Surg. 2021;25(7):1745-1759. doi:10.1007/s11605-020-04800-6

63. Hwang S, Song G-W, Lee Y-J, et al. Multiplication of Tumor Volume by Two Tumor Markers Is a Post-Resection Prognostic Predictor for Solitary Hepatocellular Carcinoma. J Gastrointest Surg. 2016;20(11):1807-1820. doi:10.1007/s11605-016-3187-y

64. Park GC. Validation of prognostic impact of ADV score for resection of hepatocellular carcinoma: analysis using Korea Liver Cancer Registry Database. Ann Surg Treat Res. 2020;98 (5):235-246. doi:10.4174/astr.2020.98.5.235

65. Hwang S. Prognostic Prediction Models for Resection of Large Hepatocellular Carcinoma: a Korean Multicenter Study. World J Surg. 2018;42(8):2579-2591. doi:10.1007/s00268-018-4468-2

66. Matono R, Yoshiya S, Motomura T, et al. Factors linked to longterm survival of patients with hepatocellular carcinoma accompanied by tumour thrombus in the major portal vein after surgical resection. HPB. 2012;14(4):247-253. doi:10.1111/j.1477-2574.2011.00436.x

67. Chai ZT, Zhang X-P, Shao M, et al. Impact of splenomegaly and splenectomy on prognosis in hepatocellular carcinoma with portal vein tumor thrombus treated with hepatectomy. Ann Transl Med. 2021;9(3):247. doi:10.21037/atm-20-2229

68. Bruix J, Raoul J-L, Sherman M, et al. Efficacy and safety of sorafenib in patients with advanced hepatocellular carcinoma: subanalyses of a phase III trial. J Hepatol. 2012;57(4):821-829. doi:10.1016/j.jhep.2012.06.014 
69. Kudo M, Finn RS, Qin S, et al. Lenvatinib versus sorafenib in first-line treatment of patients with unresectable hepatocellular carcinoma: a randomised Phase 3 non-inferiority trial. Lancet. 2018;391(10126):1163-1173. doi:10.1016/S0140-6736(18)30207-1

70. Finn Richard RS, Qin S, Ikeda M, et al. Atezolizumab plus Bevacizumab in Unresectable Hepatocellular Carcinoma. $N$ Engl J Med. 2020;382(20):1894-1905. doi:10.1056/NEJMoa1915745

71. Galle PR, Finn RS, Qin S, et al. Patient-reported outcomes with atezolizumab plus bevacizumab versus sorafenib in patients with unresectable hepatocellular carcinoma (IMbrave150): an open-label, randomised, phase 3 trial. Lancet Oncol. 2021;22 (7):991-1001. doi:10.1016/S1470-2045(21)00151-0

72. Bruix J, Qin S, Merle P, et al. Regorafenib for patients with hepatocellular carcinoma who progressed on sorafenib treatment (RESORCE): a randomised, double-blind, placebo-controlled, phase 3 trial. Lancet. 2017;389(10064):56-66. doi:10.1016/ S0140-6736(16)32453-9

73. Zhu AX. Ramucirumab after sorafenib in patients with advanced hepatocellular carcinoma and increased $\alpha$-fetoprotein concentrations (REACH-2): a randomised, double-blind, placebocontrolled, phase 3 trial. Lancet Oncol. 2019;20(2):282-296. doi:10.1016/S1470-2045(18)30937-9

74. Abou-Alfa GK, Meyer T, Cheng A-L, et al. Cabozantinib in Patients with Advanced and Progressing Hepatocellular Carcinoma. N Engl J Med. 2018;379(1):54-63. doi:10.1056/ NEJMoa1717002

75. El-Khoueiry AB, Sangro B, Yau T, et al. Nivolumab in patients with advanced hepatocellular carcinoma (CheckMate 040): an open-label, non-comparative, Phase 1/2 dose escalation and expansion trial. Lancet. 2017;389(10088):2492-2502. doi:10.1016/S0140-6736(17)31046-2

76. Yau T. Nivolumab in advanced hepatocellular carcinoma: sorafenib-experienced Asian cohort analysis. J Hepatol. 2019;71 (3):543-552.

77. Zhu AX, Finn RS, Edeline J, et al. Pembrolizumab in patients with advanced hepatocellular carcinoma previously treated with sorafenib (KEYNOTE-224): a non-randomised, open-label Phase 2 trial. Lancet Oncol. 2018;19(7):940-952. doi:10.1016/S14702045(18)30351-6

78. Allen C, Her S, Jaffray DA. Radiotherapy for Cancer: present and Future. Adv Drug Deliv Rev. 2017;109:1-2. doi:10.1016/j. addr.2017.01.004

79. Citrin DE, Longo DL. Recent Developments in Radiotherapy. $N$ Engl J Med. 2017;377(11):1065-1075. doi:10.1056/NEJMra1608986

80. Jarosz-Biej M. Tumor Microenvironment as A "Game Changer" in Cancer Radiotherapy. Int J Mol Sci. 2019;20(13):3212. doi:10.3390/ijms20133212

81. Sharma H. Role of external beam radiation therapy in management of hepatocellular carcinoma. J Clin Exp Hepatol. 2014;4 (Suppl 3):S122-5. doi:10.1016/j.jceh.2014.05.002

82. Chen CP. Role of External Beam Radiotherapy in Hepatocellular Carcinoma. Clin Liver Dis. 2020;24(4):701-717. doi:10.1016/j. cld.2020.07.006

83. Rim $\mathrm{CH}$, Kim CY, Yang DS, et al. Comparison of radiation therapy modalities for hepatocellular carcinoma with portal vein thrombosis: a meta-analysis and systematic review. Radiother Oncol. 2018;129(1):112-122. doi:10.1016/j.radonc.2017.11.013

84. Lee JS, Kim BK, Kim SU, et al. A survey on transarterial chemoembolization refractoriness and a real-world treatment pattern for hepatocellular carcinoma in Korea. Clin Mol Hepatol. 2020;26(1):24-32. doi:10.3350/cmh.2018.0065

85. Yoon SM, Ryoo B-Y, Lee SJ, et al. Efficacy and Safety of Transarterial Chemoembolization Plus External Beam Radiotherapy vs Sorafenib in Hepatocellular Carcinoma With Macroscopic Vascular Invasion: a Randomized Clinical Trial. JAMA Oncol. 2018;4(5):661-669. doi:10.1001/jamaoncol.2017.5847
86. Bai S, Wu Y, Yan Y, et al. Evaluation of the Efficacy and Toxicity of Radiotherapy for Type III-IV Portal Vein Tumor Thrombi. Technol Cancer Res Treat. 2021;20:1533033821995286. doi:10.1177/1533033821995286

87. Nakazawa T, Hidaka H, Shibuya A, et al. Overall survival in response to sorafenib versus radiotherapy in unresectable hepatocellular carcinoma with major portal vein tumor thrombosis: propensity score analysis. BMC Gastroenterol. 2014;14:84. doi:10.1186/1471-230X-14-84

88. Kosaka Y, Kimura T, Kawaoka T, et al. Hepatic Arterial Infusion Chemotherapy Combined with Radiation Therapy for Advanced Hepatocellular Carcinoma with Tumor Thrombosis of the Main Trunk or Bilobar of the Portal Vein. Liver Cancer. 2021;10 (2):151-160. doi:10.1159/000513706

89. Zhao Y. Safety and Efficacy of Transcatheter Arterial Chemoembolization Plus Radiotherapy Combined With Sorafenib in Hepatocellular Carcinoma Showing Macrovascular Invasion. Front Oncol. 2019;9:1065. doi:10.3389/fonc.2019.01065

90. Zhang XB, Wang J-H, Yan Z-P, et al. Hepatocellular carcinoma with main portal vein tumor thrombus: treatment with 3-dimensional conformal radiotherapy after portal vein stenting and transarterial chemoembolization. Cancer. 2009;115 (6):1245-1252. doi:10.1002/cncr.24139

91. Fujino H, Kimura T, Aikata H, et al. Role of 3-D conformal radiotherapy for major portal vein tumor thrombosis combined with hepatic arterial infusion chemotherapy for advanced hepatocellular carcinoma. Hepatol Res. 2015;45(6):607-617. doi:10.1111/hepr.12392

92. Huo YR, Eslick GD. Transcatheter Arterial Chemoembolization Plus Radiotherapy Compared With Chemoembolization Alone for Hepatocellular Carcinoma: a Systematic Review and Meta-analysis. JAMA Oncol. 2015;1(6):756-765. doi:10.1001/ jamaoncol.2015.2189

93. Aguirre-Ghiso JA. Models, mechanisms and clinical evidence for cancer dormancy. Nat Rev Cancer. 2007;7(11):834-846. doi:10.1038/nrc2256

94. Steel GG, Peckham MJ. Exploitable mechanisms in combined radiotherapy-chemotherapy: the concept of additivity. Int J Radiat Oncol Biol Phys. 1979;5(1):85-91. doi:10.1016/ 0360-3016(79)90044-0

95. Chen WJ. Three-dimensional conformal radiotherapy in combination with transcatheter arterial chemoembolization in the treatment of hepatocellular carcinoma. J buon. 2014;19 (3):692-697.

96. Han S, Lee HW, Park JY, et al. Appraisal of Long-Term Outcomes of Liver-Directed Concurrent Chemoradiotherapy for Hepatocellular Carcinoma with Major Portal Vein Invasion. $J$ Hepatocell Carcinoma. 2020;7:403-412. doi:10.2147/JHC.S276528

97. Jin Y, Choi MD, Jeong I. The possibility of radiotherapy as downstaging to living donor liver transplantation for hepatocellular carcinoma with portal vein tumor thrombus. Liver Transpl. 2017;23(4):545-551.

98. Kishore SA, Bajwa R, Madoff DC. Embolotherapeutic Strategies for Hepatocellular Carcinoma: 2020 Update. Cancers (Basel). 2020;12(4):791. doi:10.3390/ cancers 12040791

99. Ltd.”, S.S.-S.P. SIR-Spheres microspheres. Clinicians >About SIR-Spheres microspheres; 2021. Available from: https://www. sirtex.com/au/clinicians/about-sir-spheres-microspheres/. Accessed August 19, 2021.

100. Corporation BS. TheraSphere ${ }^{\mathrm{TM}}$ Y-90 Glass Microspheres; 2021. Available from: https://www.bostonscientific.com/enUS/products/cancer-therapies/therasphere-y90-glassmicrospheres/product-specifications.html. Accessed August $19,2021$. 
101. Vilgrain V, Pereira H, Assenat E, et al. Efficacy and safety of selective internal radiotherapy with yttrium-90 resin microspheres compared with sorafenib in locally advanced and inoperable hepatocellular carcinoma (SARAH): an open-label randomised controlled phase 3 trial. Lancet Oncol. 2017;18(12):1624-1636. doi:10.1016/S1470-2045(17)30683-6

102. Chow PKH, Gandhi M, Tan S-B, et al. SIRveNIB: selective Internal Radiation Therapy Versus Sorafenib in Asia-Pacific Patients With Hepatocellular Carcinoma. J Clin Oncol. 2018;36 (19):1913-1921. doi:10.1200/JCO.2017.76.0892

103. Ricke J, Klümpen HJ, Amthauer $\mathrm{H}$, et al. Impact of combined selective internal radiation therapy and sorafenib on survival in advanced hepatocellular carcinoma. J Hepatol. 2019;71 (6):1164-1174. doi:10.1016/j.jhep.2019.08.006

104. Edeline J, Crouzet L, Campillo-Gimenez B, et al. Selective internal radiation therapy compared with sorafenib for hepatocellular carcinoma with portal vein thrombosis. Eur J Nucl Med Mol Imaging. 2016;43(4):635-643. doi:10.1007/s00259-015-3210-7

105. Xing M, Kokabi N, Camacho JC, et al. Prospective longitudinal quality of life and survival outcomes in patients with advanced infiltrative hepatocellular carcinoma and portal vein thrombosis treated with Yttrium-90 radioembolization. BMC Cancer. 2018;18(1):75. doi:10.1186/s12885-017-3921-1

106. Chew V, Lee YH, Pan L, et al. Immune activation underlies a sustained clinical response to Yttrium-90 radioembolisation in hepatocellular carcinoma. Gut. 2019;68(2):335-346. doi:10.1136/ gutjnl-2017-315485

107. Garin E, Rolland Y, Edeline J. 90Y-Loaded Microsphere SIRT of HCC Patients With Portal Vein Thrombosis: high Clinical Impact of 99mTc-MAA SPECT/CT-Based Dosimetry. Semin Nucl Med. 2019;49(3):218-226. doi:10.1053/j.semnuclmed.2019.01.006

108. Curley SA, Hohn DC, Roh MS. Hepatic artery infusion pumps: cannulation techniques and other surgical considerations. Langenbecks Arch Chir. 1990;375(2):119-124. doi:10.1007/ BF00713397

109. Song MJ, Bae SH. Newer treatments for advanced hepatocellular carcinoma. Korean J Intern Med. 2014;29(2):149-155. doi:10.3904/kjim.2014.29.2.149

110. Lyu N, Kong Y, Mu L, et al. Hepatic arterial infusion of oxaliplatin plus fluorouracil/leucovorin vs. sorafenib for advanced hepatocellular carcinoma. $J$ Hepatol. 2018;69(1):60-69. doi:10.1016/j.jhep.2018.02.008

111. Song DS, Song MJ, Bae SH, et al. A comparative study between sorafenib and hepatic arterial infusion chemotherapy for advanced hepatocellular carcinoma with portal vein tumor thrombosis. $J$ Gastroenterol. 2015;50(4):445-454. doi:10.1007/s00535-0140978-3

112. Choi JH, Chung WJ, Bae SH, et al. Randomized, prospective, comparative study on the effects and safety of sorafenib vs hepatic arterial infusion chemotherapy in patients with advanced hepatocellular carcinoma with portal vein tumor thrombosis. Cancer Chemother Pharmacol. 2018;82(3):469-478. doi:10.1007/s00280-018-3638-0

113. Iwamoto H, Niizeki T, Nagamatsu H, et al. Survival Benefit of Hepatic Arterial Infusion Chemotherapy over Sorafenib in the Treatment of Locally Progressed Hepatocellular Carcinoma. Cancers (Basel). 2021;13(4):646. doi:10.3390/cancers 13040646

114. Ueshima K, Ogasawara S, Ikeda M, et al. Hepatic Arterial Infusion Chemotherapy versus Sorafenib in Patients with Advanced Hepatocellular Carcinoma. Liver Cancer. 2020;9 (5):583-595. doi:10.1159/000508724

115. Ahn YE, Suh SJ, Yim HJ, et al. Comparison of Sorafenib versus Hepatic Arterial Infusion Chemotherapy-Based Treatment for Advanced Hepatocellular Carcinoma with Portal Vein Tumor Thrombosis. Gut Liver. 2021;15(2):284-294. doi:10.5009/ gn119367
116. Moriguchi M, Aramaki T, Nishiofuku H, et al. Sorafenib versus Hepatic Arterial Infusion Chemotherapy as Initial Treatment for Hepatocellular Carcinoma with Advanced Portal Vein Tumor Thrombosis. Liver Cancer. 2017;6(4):275-286. doi:10.1159/ 000473887

117. Ikeda M, Shimizu S, Sato T, et al. Sorafenib plus hepatic arterial infusion chemotherapy with cisplatin versus sorafenib for advanced hepatocellular carcinoma: randomized phase II trial. Ann Oncol. 2016;27(11):2090-2096. doi:10.1093/annonc/ mdw323

118. Kudo M, Ueshima K, Yokosuka O, et al. Sorafenib plus low-dose cisplatin and fluorouracil hepatic arterial infusion chemotherapy versus sorafenib alone in patients with advanced hepatocellular carcinoma (SILIUS): a randomised, open label, phase 3 trial. Lancet Gastroenterol Hepatol. 2018;3(6):424-432. doi:10.1016/ S2468-1253(18)30078-5

119. He M, Li Q, Zou R, et al. Sorafenib Plus Hepatic Arterial Infusion of Oxaliplatin, Fluorouracil, and Leucovorin vs Sorafenib Alone for Hepatocellular Carcinoma With Portal Vein Invasion: a Randomized Clinical Trial. JAMA Oncol. 2019;5(7):953-960. doi:10.1001/jamaoncol.2019.0250

120. Kawaoka T, Aikata H, Hyogo H, et al. Comparison of hepatic arterial infusion chemotherapy versus sorafenib monotherapy in patients with advanced hepatocellular carcinoma. J Dig Dis. 2015;16(9):505-512. doi:10.1111/1751-2980.12267

121. Kodama K, Kawaoka T, Aikata H, et al. Comparison of Outcome of Hepatic Arterial Infusion Chemotherapy Combined with Radiotherapy and Sorafenib for Advanced Hepatocellular Carcinoma Patients with Major Portal Vein Tumor Thrombosis. Oncology. 2018;94(4):215-222. doi:10.1159/000486483

122. Liu BJ. Sorafenib combined with embolization plus hepatic arterial infusion chemotherapy for inoperable hepatocellular carcinoma. World J Gastrointest Oncol. 2020;12(6):663-676. doi:10.4251/wjgo.v12.i6.663

123. Mei J, Li S-H, Li Q-J, et al. Anti-PD-1 Immunotherapy Improves the Efficacy of Hepatic Artery Infusion Chemotherapy in Advanced Hepatocellular Carcinoma. J Hepatocell Carcinoma. 2021;8:167-176. doi:10.2147/JHC.S298538

124. Konno T, Maeda H, Iwai K, et al. Effect of arterial administration of high-molecular-weight anticancer agent SMANCS with lipid lymphographic agent on hepatoma: a preliminary report. Eur J Cancer Clin Oncol. 1983;19(8):1053-1065. doi:10.1016/02775379(83)90028-7

125. Doyon D, Mouzon A, Jourde AM, et al. [Hepatic, arterial embolization in patients with malignant liver tumours (author's transl)]. Annales de radiologie. 1974;17(6):593-603. French.

126. Ryusaku Yamada KK, Terada M, Sonomura T, Sato M, Primary Liver Cancer in Japan, 1992, in Primary Liver Cancer in Japan, 1992. Springer. Part of Springer Nature; 2016.

127. Ohishi H, Uchida H, Yoshimura H, et al. Hepatocellular carcinoma detected by iodized oil. Use of anticancer agents. Radiology. 1985;154(1):25-29. doi:10.1148/ radiology.154.1.2981114

128. Golfieri R, Giampalma E, Renzulli M, et al. Randomised controlled trial of doxorubicin-eluting beads vs conventional chemoembolisation for hepatocellular carcinoma. $\mathrm{Br} J$ Cancer. 2014;111(2):255-264. doi:10.1038/bjc.2014.199

129. Lammer J, Malagari K, Vogl T, et al. Prospective randomized study of doxorubicin-eluting-bead embolization in the treatment of hepatocellular carcinoma: results of the PRECISION V study. Cardiovasc Intervent Radiol. 2010;33(1):41-52. doi:10.1007/ s00270-009-9711-7

130. Facciorusso A, Di Maso M, Muscatiello N. Drug-eluting beads versus conventional chemoembolization for the treatment of unresectable hepatocellular carcinoma: a meta-analysis. Dig Liver Dis. 2016;48(6):571-577. doi:10.1016/j.dld.2016.02.005 
131. Kloeckner R, Weinmann A, Prinz F, et al. Conventional transarterial chemoembolization versus drug-eluting bead transarterial chemoembolization for the treatment of hepatocellular carcinoma. BMC Cancer. 2015;15(1):465. doi:10.1186/s12885015-1480-x

132. Lv WF.Transarterial chemoembolization for hepatocellular carcinoma combined with portal vein tumor thrombosis. Cancer Manag Res. 2018;10:4719-4726. doi:10.2147/CMAR.S166527

133. Lencioni R, de Baere T, Soulen MC, et al. Lipiodol transarterial chemoembolization for hepatocellular carcinoma: a systematic review of efficacy and safety data. Hepatology. 2016;64 (1):106-116. doi:10.1002/hep.28453

134. Zhu K, Chen J, Lai L, et al. Hepatocellular carcinoma with portal vein tumor thrombus: treatment with transarterial chemoembolization combined with sorafenib-a retrospective controlled study. Radiology. 2014;272(1):284-293. doi:10.1148/radiol.14131946

135. Liu KC, Hao Y-H, Lv W-F, et al. Transarterial Chemoembolization Combined with Sorafenib in Patients with BCLC Stage C Hepatocellular Carcinoma. Drug Des Devel Ther. 2020;14:3461-3468. doi:10.2147/DDDT.S248850

136. Fan W. Apatinib Combined With Transarterial Chemoembolization in Patients With Hepatocellular Carcinoma and Portal Vein Tumor Thrombus: a Multicenter Retrospective Study. Clin Ther. 2019;41(8):1463-1476. doi:10.1016/j. clinthera.2019.04.036

137. Pan T, Li X-S, Xie Q-K, et al. Safety and efficacy of transarterial chemoembolization plus sorafenib for hepatocellular carcinoma with portal venous tumour thrombus. Clin Radiol. 2014;69(12): e553-61. doi:10.1016/j.crad.2014.09.007

138. Ding X, Sun W, Li W, et al. Transarterial chemoembolization plus lenvatinib versus transarterial chemoembolization plus sorafenib as first-line treatment for hepatocellular carcinoma with portal vein tumor thrombus: a prospective randomized study. Cancer. 2021. doi:10.1002/cncr.33677

139. Zhang ZH, Liu Q-X, Zhang W, et al. Combined endovascular brachytherapy, sorafenib, and transarterial chemobolization therapy for hepatocellular carcinoma patients with portal vein tumor thrombus. World J Gastroenterol. 2017;23(43):7735-7745. doi:10.3748/wjg.v23.i43.7735

140. Luo JJ, Zhang Z-H, Liu Q-X, et al. Endovascular brachytherapy combined with stent placement and TACE for treatment of HCC with main portal vein tumor thrombus. Hepatol Int. 2016;10 (1):185-195. doi:10.1007/s12072-015-9663-8

141. Huang M, Lin Q, Wang H, et al. Survival benefit of chemoembolization plus Iodine 125 seed implantation in unresectable hepatitis B-related hepatocellular carcinoma with PVTT: a retrospective matched cohort study. Eur Radiol. 2016;26(10):3428-3436. doi:10.1007/s00330-015-4198-x

142. Kim GA, Shim JH, Yoon SM, et al. Comparison of chemoembolization with and without radiation therapy and sorafenib for advanced hepatocellular carcinoma with portal vein tumor thrombosis: a propensity score analysis. J Vasc Interv Radiol. 2015;26 (3):320-9.e6. doi:10.1016/j.jvir.2014.10.019

143. Zhou TY, Chen S-Q, Wang H-L, et al. Safety and efficacy of drug-eluting bead transarterial chemoembolization with CalliSpheres ${ }^{\circledR}$ microsphere for hepatocellular carcinoma with portal vein tumor thrombus: a preliminary study. $J$ Cancer. 2021;12(15):4522-4529. doi:10.7150/jca.54650

144. Yamaoka Y, Kumada K, Ino K, et al. Liver resection for hepatocellular carcinoma (HCC) with direct removal of tumor thrombi in the main portal vein. World J Surg. 1992;16(6):1172-6; discussion 1177. doi:10.1007/BF02067093

145. Peng SY. Better surgical treatment method for hepatocellular carcinoma with portal vein tumor thrombus. World $J$ Gastroenterol. 2018;24(40):4527-4535. doi:10.3748/wjg.v24. $\mathrm{i} 40.4527$
146. Glantzounis GK, Paliouras A, Stylianidi M-C, et al. The role of liver resection in the management of intermediate and advanced stage hepatocellular carcinoma. A systematic review. Eur J Surg Oncol. 2018;44(2):195-208. doi:10.1016/j.ejso.2017.11.022

147. Konishi M, et al. Surgical treatment of hepatocellular carcinoma with direct removal of the tumor thrombus in the main portal vein. Hepatogastroenterology. 2001;48(41):1421-1424.

148. Cheng S, Chen M, Cai J, et al. Chinese Expert Consensus on Multidisciplinary Diagnosis and Treatment of Hepatocellular Carcinoma with Portal Vein Tumor Thrombus (2018 Edition). Liver Cancer. 2020;9(1):28-40. doi:10.1159/000503685

149. Liang L, Chen T-H, Li C, et al. A systematic review comparing outcomes of surgical resection and non-surgical treatments for patients with hepatocellular carcinoma and portal vein tumor thrombus. HPB (Oxford). 2018;20(12):1119-1129. doi:10.1016/j. hpb.2018.06.1804

150. Higaki T, Yamazaki S, Moriguchi M, et al. Indication for surgical resection in patients with hepatocellular carcinoma with major vascular invasion. Biosci Trends. 2017;11(5):581-587. doi:10.5582/bst.2017.01210

151. Mähringer-Kunz A. Extent of portal vein tumour thrombosis in patients with hepatocellular carcinoma: the more, the worse? Liver Int. 2019;39(2):324-331. doi:10.1111/liv.13988

152. Kokudo T. Survival benefit of liver resection for hepatocellular carcinoma associated with portal vein invasion. J Hepatol. 2016;65(5):938-943. doi:10.1016/j.jhep.2016.05.044

153. Shi J. Surgical treatment of hepatocellular carcinoma with portal vein tumor thrombus. Ann Surg Oncol. 2010;17(8):2073-2080. doi:10.1245/s10434-010-0940-4

154. Chen ZH. Actual long-term survival in HCC patients with portal vein tumor thrombus after liver resection: a nationwide study. Hepatol Int. 2020;14(5):754-764. doi:10.1007/s12072-02010032-2

155. Roayaie S, Jibara G, Taouli B, et al. Resection of hepatocellular carcinoma with macroscopic vascular invasion. Ann Surg Oncol. 2013;20(12):3754-3760. doi:10.1245/s10434-013-3074-7

156. Ikai I, Yamaoka Y, Yamamoto Y, et al. Surgical intervention for patients with stage IV-A hepatocellular carcinoma without lymph node metastasis: proposal as a standard therapy. Ann Surg. 1998;227(3):433-439. doi:10.1097/00000658-199803000-00016

157. Ikai I, Hatano E, Hasegawa S, et al. Prognostic index for patients with hepatocellular carcinoma combined with tumor thrombosis in the major portal vein. J Am Coll Surg. 2006;202(3):431-438. doi:10.1016/j.jamcollsurg.2005.11.012

158. Ohkubo T, Yamamoto J, Sugawara Y, et al. Surgical results for hepatocellular carcinoma with macroscopic portal vein tumor thrombosis. J Am Coll Surg. 2000;191(6):657-660. doi:10.1016/ S1072-7515(00)00740-7

159. Chen XP, Qiu F-Z, Wu Z-D, et al. Effects of location and extension of portal vein tumor thrombus on long-term outcomes of surgical treatment for hepatocellular carcinoma. Ann Surg Oncol. 2006;13(7):940-946. doi:10.1245/ASO.2006.08.007

160. Kudo M, Izumi N, Ichida T, et al. Report of the 19th follow-up survey of primary liver cancer in Japan. Hepatol Res. 2016;46 (5):372-390. doi:10.1111/hepr.12697

161. Pesi B, Ferrero A, Grazi GL, et al. Liver resection with thrombectomy as a treatment of hepatocellular carcinoma with major vascular invasion: results from a retrospective multicentric study. Am J Surg. 2015;210(1):35-44. doi:10.1016/j.amjsurg.2014. 09.041

162. Zhang XP, Wang K, Li N, et al. Survival benefit of hepatic resection versus transarterial chemoembolization for hepatocellular carcinoma with portal vein tumor thrombus: a systematic review and meta-analysis. BMC Cancer. 2017;17(1):902. doi:10.1186/s12885-017-3895-z 
163. Hyun MH, Lee Y-S, Kim JH, et al. Hepatic resection compared to chemoembolization in intermediate- to advanced-stage hepatocellular carcinoma: a meta-analysis of high-quality studies. Hepatology. 2018;68(3):977-993. doi:10.1002/hep.29883

164. Sieghart W, Hucke F, Peck-Radosavljevic M. Transarterial chemoembolization: modalities, indication, and patient selection. $J$ Hepatol. 2015;62(5):1187-1195. doi:10.1016/j.jhep.2015.02.010

165. Peng ZW, Guo R-P, Zhang Y-J, et al. Hepatic resection versus transcatheter arterial chemoembolization for the treatment of hepatocellular carcinoma with portal vein tumor thrombus. Cancer. 2012;118(19):4725-4736. doi:10.1002/cncr.26561

166. Liu PH, Lee Y-H, Hsia C-Y, et al. Surgical resection versus transarterial chemoembolization for hepatocellular carcinoma with portal vein tumor thrombosis: a propensity score analysis. Ann Surg Oncol. 2014;21(6):1825-1833. doi:10.1245/s10434-014-3510-3

167. Zhang YF, Guo R-P, Zou R-H, et al. Efficacy and safety of preoperative chemoembolization for resectable hepatocellular carcinoma with portal vein invasion: a prospective comparative study. Eur Radiol. 2016;26(7):2078-2088. doi:10.1007/s00330015-4021-8

168. Li N, Feng S, Xue J, et al. Hepatocellular carcinoma with main portal vein tumor thrombus: a comparative study comparing hepatectomy with or without neoadjuvant radiotherapy. $H P B$ (Oxford). 2016;18(6):549-556. doi:10.1016/j.hpb.2016.04.003

169. Hamaoka M, Kobayashi T, Kuroda S, et al. Hepatectomy after down-staging of hepatocellular carcinoma with portal vein tumor thrombus using chemoradiotherapy: a retrospective cohort study. Int J Surg. 2017;44:223-228. doi:10.1016/j.ijsu.2017.06.082

170. Wei X, Jiang Y, Zhang X, et al. Neoadjuvant Three-Dimensional Conformal Radiotherapy for Resectable Hepatocellular Carcinoma With Portal Vein Tumor Thrombus: a Randomized, Open-Label, Multicenter Controlled Study. J Clin Oncol. 2019;37 (24):2141-2151. doi:10.1200/JCO.18.02184

171. Liang L, Li C, Diao Y-K, et al. Survival benefits from adjuvant transcatheter arterial chemoembolization in patients undergoing liver resection for hepatocellular carcinoma: a systematic review and meta-analysis. Therap Adv Gastroenterol. 2020;13:1756284820977693. doi:10.1177/1756284820977693

172. Huang S, Li D, Zhuang L, et al. A meta-analysis of the efficacy and safety of adjuvant sorafenib for hepatocellular carcinoma after resection. World J Surg Oncol. 2021;19(1):168. doi:10.1186/s12957-021-02280-9

173. Liu J, Wang Y, Zhang D, et al. Comparison of survival and quality of life of hepatectomy and thrombectomy using total hepatic vascular exclusion and chemotherapy alone in patients with hepatocellular carcinoma and tumor thrombi in the inferior vena cava and hepatic vein. Eur J Gastroenterol Hepatol. 2012;24 (2):186-194. doi:10.1097/MEG.0b013e32834dda64
174. Panayotova G, Lunsford KE, Latt NL, et al. Expanding indications for liver transplantation in the era of liver transplant oncology. World J Gastrointest Surg. 2021;13(5):392-405. doi:10.4240/wjgs.v13.i5.392

175. Ju MR, Yopp AC. Evolving thresholds for liver transplantation in hepatocellular carcinoma: a Western experience. Ann Gastroenterol Surg. 2020;4(3):208-215. doi:10.1002/ags3.12316

176. Bruix J. Liver transplantation for hepatocellular carcinoma: Foucault pendulum versus evidence-based decision. Liver Transpl. 2003;9(7):700-702. doi:10.1053/jlts.2003.50124

177. Volk ML, Vijan S, Marrero JA. A novel model measuring the harm of transplanting hepatocellular carcinoma exceeding Milan criteria. Am J Transplant. 2008;8(4):839-846. doi:10.1111/j.16006143.2007.02138.x

178. $\mathrm{Xu} \mathrm{X}$. Orthotopic liver transplantation for patients with hepatocellular carcinoma complicated by portal vein tumor thrombi. Hepatobiliary Pancreat Dis Int. 2004;3(3):341-344.

179. Choi HJ, Kim DG, Na GH, et al. The clinical outcomes of patients with portal vein tumor thrombi after living donor liver transplantation. Liver Transpl. 2017;23(8):1023-1031. doi:10.1002/lt.24782

180. Lee KW. Macrovascular invasion is not an absolute contraindication for living donor liver transplantation. Liver Transpl. 2017;23 (1):19-27. doi:10.1002/lt.24610

181. Ma KW, Chan ACY, Chok KSH, et al. Liver transplantation: would it be the best and last chance of cure for hepatocellular carcinoma with major venous invasion? Hepatobiliary Surg Nutr. 2021;10(3):308-314. doi:10.21037/hbsn.2020.03.09

182. Lv JY. Comparison of Liver Transplantation and Liver Resection for Hepatocellular Carcinoma Patients with Portal Vein Tumor Thrombus Type I and Type II. Yonsei Med J. 2021;62(1):29-40. doi:10.3349/ymj.2021.62.1.29

183. Chapman WC, Majella Doyle MB, Stuart JE, et al. Outcomes of neoadjuvant transarterial chemoembolization to downstage hepatocellular carcinoma before liver transplantation. Ann Surg. 2008;248(4):617-625. doi:10.1097/SLA.0b013e31818a07d4

184. Jeong Y, Shin M-H, Yoon SM, et al. Liver Transplantation After Transarterial Chemoembolization and Radiotherapy for Hepatocellular Carcinoma with Vascular Invasion. J Gastrointest Surg. 2017;21(2):275-283. doi:10.1007/s11605-016-3302-0
Journal of Hepatocellular Carcinoma

\section{Publish your work in this journal}

The Journal of Hepatocellular Carcinoma is an international, peerreviewed, open access journal that offers a platform for the dissemination and study of clinical, translational and basic research findings in this rapidly developing field. Development in areas including, but not limited to, epidemiology, vaccination, hepatitis therapy, pathology and molecular tumor classification and prognostication are all considered for publication. The manuscript management system is completely online and includes a very quick and fair peer-review system, which is all easy to use. Visit http://www.dovepress.com/ testimonials.php to read real quotes from published authors. 